\title{
UNDERSTANDING HOW DISEASE AND ENVIRONMENT COMBINE TO STRUCTURE RESISTANCE IN ESTUARINE BIVALVE POPULATIONS
}

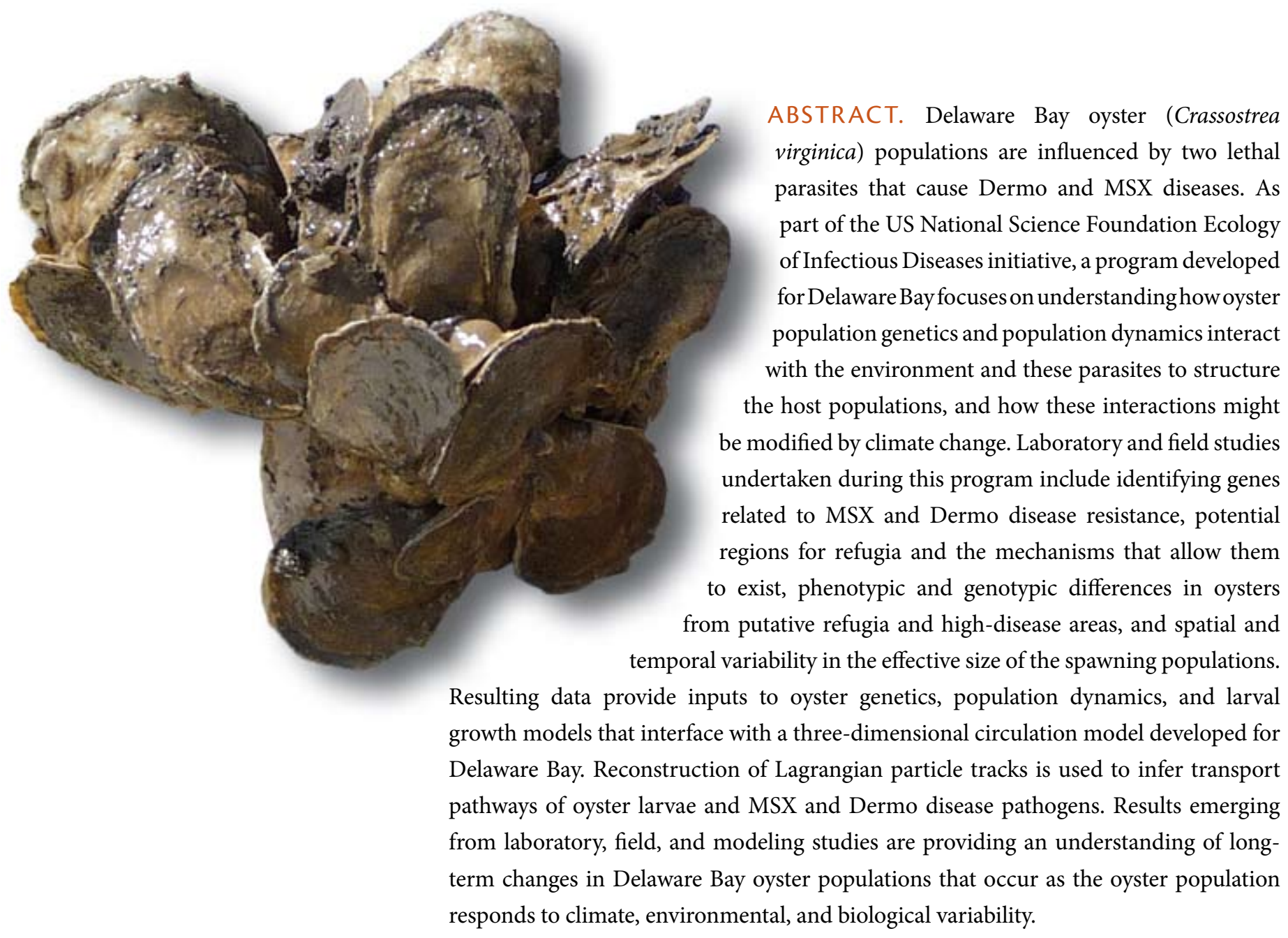




\section{INTRODUCTION}

Diseases of bivalve molluscs are noteworthy not only for their impact on population dynamics, especially of key commercial species, but also for characteristics that separate them from typical diseases affecting mammals and fish. Most described bivalve diseases are of protozoan origin (Bower et al., 1994) and transmission is via the water column, as adult hosts are immobile. Transmission can occur over large distances and can be swift under favorable climatic conditions, resulting in rapid parasite proliferation and mass adult mortalities (Andrews and Wood, 1967; Lafferty and Kuris, 1993; Burreson and Ragone Calvo, 1996; Ford, 1996). Throughout the region in which a disease is enzootic (see Box 1 for definitions of terms used in this article), most hosts are exposed and probably become infected, even though infections may be undetected (Bushek et al., 1994; Stokes et al., 1996; Culloty et al., 2003).

Bivalves do not obey the classic Kermack and McKendrick (1927) disease model, which is based on hostto-host contact rate as the prime determinant of transmission. Bivalve molluscs are typically sessile, and individuals do not become resistant and develop immunity after becoming exposed in the standard "Susceptible, Infectious, Recovered" (SIR) models often used to simulate disease for vertebrate populations (Kermack and McKendrick, 1927; Ackerman et al., 1984; Hufnagel et al., 2004). Epizootics in bivalve populations are controlled more by the environment than by host density. Bivalves exhibit varying capabilities to develop genetically based resistance to disease caused by parasites (Haskin and Ford, 1979; Gaffney and Bushek, 1996;
Ford et al., 2002; Nell and Hand, 2003; Ragone Calvo et al., 2003), but populations may maintain themselves as much by range contractions as by developing resistance. Disease-caused mortality of an estuarine bivalve frequently varies along spatial gradients, so that the population contracts to regions with less disease pressure (i.e., "disease refugia," see Box 1). This may reduce host population size by limiting the area of available habitat. Furthermore, the lessened selection pressure (Box 1) will likely reduce the proportion of adults that have been exposed to disease and have been selected for resistance, and of dilute disease-resistant alleles (Box 1) that have been enriched by selection.

The eastern oyster (Crassostrea virginica) is plagued by two major diseases,

\section{THE DELAWARE BAY ECOLOGY OF INFECTIOUS DISEASES (EID) GROUP}

Eileen Hofmann (hofmann@ccpo.odu.edu) is Professor, Department of Ocean, Earth and Atmospheric Sciences, Old Dominion University, Norfolk, VA, USA. David Bushek is Associate Professor, Haskin Shellfish Research Laboratory, Rutgers University, Port Norris, NJ, USA. Susan Ford is Professor Emeritus, Haskin Shellfish Research Laboratory, Rutgers University, Port Norris, NJ, USA. Ximing Guo is Professor, Haskin Shellfish Research Laboratory, Rutgers University, Port Norris, NJ, USA. Dale Haidvogel is Professor, Institute of Marine and Coastal Sciences, Rutgers University, New Brunswick, NJ, USA. Dennis Hedgecock is Professor, Department of Biological Sciences, University of Southern California, Los Angeles, CA, USA. John Klinck is Professor, Department of Ocean, Earth and Atmospheric Sciences, Old Dominion University, Norfolk, VA, USA. Coren Milbury was Postdoctoral Research Associate, Haskin Shellfish Research Laboratory, Rutgers University, Port Norris, NJ, USA, and is currently at Department of Radiation Oncology, Dana-Farber Cancer Institute, Harvard Medical School, Cambridge, MA, USA. Diego Narvaez is Graduate Research Assistant, Department of Ocean, Earth and Atmospheric Sciences, Old Dominion University, Norfolk, VA, USA. Eric Powell is Professor, Haskin Shellfish Research Laboratory, Rutgers University, Port Norris, NJ, USA. Yongping Wang is Research Associate, Haskin Shellfish Research Laboratory, Rutgers University, Port Norris, NJ, USA. Zhiren Wang is Graduate Research Assistant, Institute of Marine and Coastal Sciences, Rutgers University, New Brunswick, NJ, USA. John Wilkin is Associate Professor, Institute of Marine and Coastal Sciences, Rutgers University, New Brunswick, NJ, USA. Liusuo Zhang is Postdoctoral Research Associate, Haskin Shellfish Research Laboratory, Rutgers University, Port Norris, NJ, USA. 


\section{BOX 1. DEFINITIONS OF IMPORTANT TERMS AND CONCEPTS}

Allele: One of the variant forms of a gene or a genetic marker. Variation in inherited traits (e.g., shell color) results from different alleles. Alleles at microsatellite DNA markers are observed after gel electrophoresis as DNA fragments of different sizes.

Common Garden Experiment: Different stock, lines, or strains of organisms are grown in the same environment ("garden") so that they experience the same conditions, including exposure to natural disease pressure. Performance can then be compared without confounding factors created by differences in environmental conditions.

Disease Refugia: An area within the host range where disease is absent or sufficiently low to have little impact on the survival or reproductive success of susceptible individuals (i.e., exerts no selection pressure).

Effective Number of Parents $\left(N_{b}\right)$ : An inferred or estimated number of parents that could account for the genetic composition of a cohort of spat that shows less genetic diversity than the adult population from which it arose. In populations with discrete generations, the sum of $N_{b}$ over all cohorts might be close to the effective population size ( $N_{e}$, see following definition), but in populations with overlapping generations, the relationship between $N_{b}$ and $N_{e}$ is more complex.

Effective Population Size $\left(\boldsymbol{N}_{e}\right)$ : The size of a mathematically ideal population that has the same rate of genetic drift or inbreeding as the actual population under study. An ideal population is unaffected by selection, has a stable census size $(N)$ from generation to generation, a 1:1 sex ratio, and a binomial or Poisson distribution of the number of offspring contributed by individual adults; as a result of these conditions, $N=N_{e}$ in the ideal population, and properties, such as loss of genetic diversity owing to random genetic drift, can be precisely predicted. Actual populations depart from ideal ones in a number of ways, and population geneticists have devised ways of estimating $N_{e}$ either directly, from demographic data, or indirectly, from genetic data. The ideal condition most likely to be violated in oyster populations is binomial or Poisson variance in individual reproductive contribution (See Sweepstakes Reproductive Success).

Enzootic: Presence of disease without significantly increasing rates of mortality. Contrast to epizootic, which indicates a disease outbreak in an animal population that typically increases mortality rates.

Genetic Drift: Random changes in allelic frequencies, resulting from chance events in reproduction. Random genetic drift is stronger in populations with small effective population size, resulting in genetic differentiation among subpopulations over time.
Genetic Linkage Map: A map of genes or genetic markers based on the frequency of recombination between grandparental alleles. Suppose for two putatively linked genes, $A$ and $B$, one crosses two individuals, $A B / / A B$ and $a b / / a b$, where the slashes represent physical linkage on a chromosome; their offspring will all be $A B / / a b$. For backcrosses of these offspring to either parental type, the proportion of recombinant offspring (e.g., $A b / / a b$ or $a B / / A B$ ) in the second generation is a function of the physical distance between the two genes. Genetic distances are given in centiMorgan (cM), and one $\mathrm{CM}$ equals $1 \%$ of recombinants between two linked markers.

Genotype: The genetic makeup of an organism determined by its DNA sequence. For a given position on the chromosome (a locus), each diploid organism such as an oyster has two alleles (see above) that determine it genotype.

Heterozygote (adj:: heterozygous): An individual carrying two different alleles. Contrast to homozygote, an individual carrying two copies of an allele that is identical by descent or identical in state. The proportion of individuals in a population that are heterozygous at a particular marker or over a number of markers is known as the heterozygosity of the population.

Microsatellite DNA Markers: Tandem repeats of short, simple DNA sequences (one to six base pairs) at particular places in a genome. As the number of repeating units is highly variable, microsatellite DNA markers are highly polymorphic and useful for making genetic linkage maps and in population studies.

Quantitative Trait Locus (QTL) (plural: loci): A region of the genome that contains one or more genes controlling variation in a quantitative trait, such as growth or survival; the existence and location of these genes are inferred from statistical associations between genotypes at one or more markers on a genetic linkage map and from the value of the trait in the genotyped individuals.

Selection Pressure: The effectiveness of natural selection in altering the genetic composition of a population over a series of generations.

Sweepstakes Reproductive Success (SRS): Occurs when a small fraction of adults contributes the vast majority of new recruits, while the remaining adults contribute average numbers of, or no, offspring (Hedgecock, 1994). As a result of SRS, the effective number of breeders $\left(N_{b}\right)$ that produces a cohort of recruits may be much smaller than the standing number of mature adults in the population $(N)$; over several years and generations, SRS would make the effective size of the population, $N_{e}$ (see above), a small fraction of average census size $N$. 
of susceptible genotypes, resistance to MSX disease in Delaware Bay appears to be an anomaly that has allowed the native oyster population to develop a relatively high level of resistance. Oysters (and perhaps other highly fecund marine and estuarine fish and invertebrates) may undergo rapid genetic shifts resulting from successful reproduction by only a very small subset of the entire population (see definition of effective population size in Box 1; Hedgecock et al., 1992; Hedgecock, 1994). Under this scenario, the subset might be composed of highly selected individuals in a nonrefuge area, even if the majority of the population existed in the refuge. For oysters, it is clear that environmental variability, including climate change, adds another dimension to factors controlling the host-parasite interaction. Understanding how host genetics, population dynamics, and environment interact with disease organisms to structure host populations, and how climate change may interact with these interrelated phenomena, is critical to the development of management and restoration strategies for the severely depleted eastern oyster stocks along the US east coast (Coen and Luckenbach, 2000).

Present understanding of host-parasite interactions is inadequate to address issues of climate change impacts on marine and estuarine invertebrates. Thus, the first emphasis must be on understanding the ways that disease structures host populations and the mechanisms

Figure 1. The host and parasites. (A) The eastern oyster, Crassostrea virginica. (B) Examples of the effect of disease on oyster condition. Note the creamy appearance of the healthy oyster, which is due to the accumulation and storage of glycogen, vs. the emaciated, glassy appearance of the diseased oyster, which has been unable to accumulate glycogen. The dark-colored digestive gland is visible through the almost transparent flesh of the diseased oyster. (C) A stained section of two MSX plasmodia showing the multiple nuclei that gave the parasite its name (Multinucleated Sphere Unknown). Note the oyster blood cell to the right of the larger plasmodium. (D) A group of MSX spores. During sporulation, the thick-walled, capped spores are formed around each nucleus in a plasmodium. Spores are presumed to be a transmission stage, but are rarely produced in adult oysters. (E) A squash of oyster tissue heavily parasitized by the Dermo parasite. The tissue has been incubated in a solution that promotes enlargement of the parasites and then stained so that they appear black. (F) Dermo parasites that have proliferated in an artificial culture medium. Scale bars $=10 \mu \mathrm{m}$ in C, D, and F; $100 \mu \mathrm{m}$ in $\mathrm{E}$.
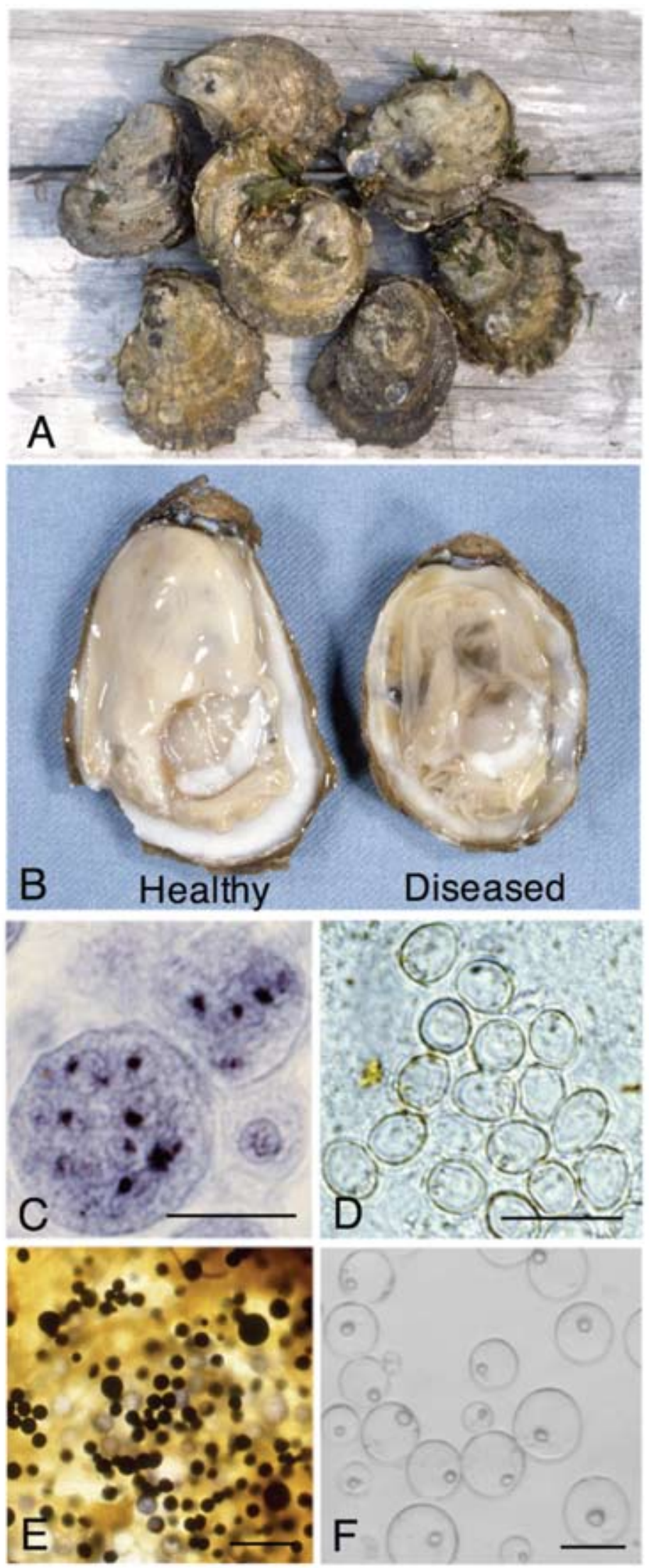
Both Dermo and MSX diseases are caused by water-borne protozoan parasites that can be lethal to oysters, but are harmless to humans (Figure 1). They belong to two separate groups of microorganisms that infect marine organisms worldwide.

The Dermo parasite, Perkinsus marinus (formerly Dermocystidium marinum), was first discovered in the Gulf of Mexico in the mid 1940 s, but it had probably been present for many years before it was identified as the cause of oyster deaths (Mackin et al., 1950). Shortly thereafter, it was found as far north as the lower Chesapeake Bay. For many years, Dermo disease was restricted primarily to the region extending from the lower Chesapeake along the southeastern United States and Gulf coasts. Beginning in the mid 1980s, coincident with a warming trend, Dermo disease outbreaks occurred progressively farther north (Ford, 1996). In 1990, an epizootic began in Delaware Bay. From 1990 through 1992, disease outbreaks occurred as far north as Cape Cod, and in 1995, oysters in southern Maine were found to be infected. Perkinsus marinus is transmitted directly between oysters, and it is likely that its northward spread was aided by historical transplantation of infected southern oysters to replenish depleted northern oyster beds.

The agent of MSX disease, Haplosporidium nelsoni, is a parasite of the Pacific oyster, Crassostrea gigas (Burreson et al., 2000). Most Pacific oysters appear to be resistant to MSX disease because infection prevalence is low and results in no reported mortalities. The parasite was introduced to the East Coast of the United States, where it found a new and highly susceptible species, the native eastern oyster, Crassostrea virginica. The first MSX outbreak, in 1957, was recorded in Delaware Bay (Haskin et al., 1966). Within two years, 90 to $95 \%$ of the oysters on the leased grounds had died. Between 1959 and 1962, the parasite was found in oysters from the Chesapeake Bay, where it also caused heavy losses, to Long Island
Sound. It is now present from Maine to Florida, although most oyster mortalities occur in the mid-Atlantic and in New England (Burreson and Ford, 2004). Direct oyster-to-oyster transmission of $\mathrm{H}$. nelsoni has never been demonstrated and another host may be necessary for the parasite to complete its life cycle.

Temperature and salinity are the primary physical controls on the parasites, driving both seasonal and longer-term cycles (Ford and Haskin, 1982; Burreson and Ragone Calvo, 1996). Both parasites are most active at elevated temperature and salinity. Oysters are much less likely to become infected, or to develop lethal infections, when they are in low-salinity waters. Therefore, selective mortality, which removes the most susceptible individuals, is reduced in the upper reaches of estuaries such as Delaware Bay. These low-salinity regions can be considered refuges from disease. Shortly after the initial MSX disease epizootic in Delaware Bay, enhanced resistance to MSX-caused mortality was observed in the native oyster population, but it failed to increase thereafter (Figure 3B). The most likely explanation is that after the 1957-1959 epizootic, most of the surviving oysters were in low-salinity refugia where they were protected from sustained selection and continued to contribute susceptible progeny to the population. This situation persisted for nearly 30 years until the droughtassociated 1984-1986 epizootic temporarily eliminated this refuge, killed a large fraction of the population, and led to a major increase in the level of resistance to MSX disease. Today, it is rare to find a native oyster with MSX disease in Delaware Bay, although susceptible oysters from other locales rapidly succumb to the disease, indicating the pathogen remains prevalent. This estuary-wide response to MSX appears to be unique to Delaware Bay. Unfortunately, Dermo disease is now widespread, causing chronic mortality, and there is little evidence that the oysters are developing resistance. by which such populations maintain themselves in the face of disease, especially in a spatially structured environment such as an estuary. Only then can we ask questions involving climate change. The eastern oyster provides one of the best opportunities for investigation of molluscan diseases capable of host population control because of the extensive knowledge available on the ecology, biology, physiology, and genetics of the species and its associated diseases.

We combined expertise in molluscan disease pathology and epizootiology; the genetics of resistance; and modeling of estuarine systems, disease processes, and genetic milieu in a collaborative project to investigate the host-parasite relationship in eastern oyster populations impacted by MSX and Dermo diseases and how it might be affected by climate change. This project was part of the National Science Foundation Ecology of Infectious Diseases (EID) initiative. Our EID project, which is focused on Delaware Bay (Figure 2), is designed to provide understanding of: (1) the time scales of selection pressure towards alleles conferring disease resistance; (2) the role of disease refugia in 
modulating population genetic structure; (3) the interplay between range contraction (resulting from epizootics) and disease resistance in preventing local extinction of host populations; and (4) the effects of a warming climate on oyster generation time, parasite transmission and proliferation, and fecundity, and consequences for shifts in the genetic structure of the host population. Our project makes use of the extensive long-term data set (1953-present) on Delaware Bay oyster populations and their diseases and a system-wide oysterdisease experiment that occurred during the mid 1980s and that resulted in a high degree of resistance to one of two disease agents present in the bay (Box 2).

The project consists of two major elements: (1) a set of field and laboratory studies focused on oyster genetics and disease dynamics, and (2) integration of genetic, environmental, population, and disease data into a series of numerical models. The field and laboratory studies implemented in this EID project are designed to determine: (1) if putative disease refugia harbor susceptible oyster populations and the mechanisms that create and maintain them, (2) if diseaseresistant genes exist and disproportionally affect population structure, and (3) if the number of parents that successfully produce offspring vary in space and time. The results from these and earlier studies underpin models that include explicit genetic structure (Hedgecock et al., 2008), disease processes (Hofmann et al., 1995; Powell et al., 1996; Ford et al., 1999; Powell et al., 1999), and post-settlement (Powell et al., 1992; Hofmann et al., 1992) and larval (Dekshenieks et al., 1996, 1997) population processes. These

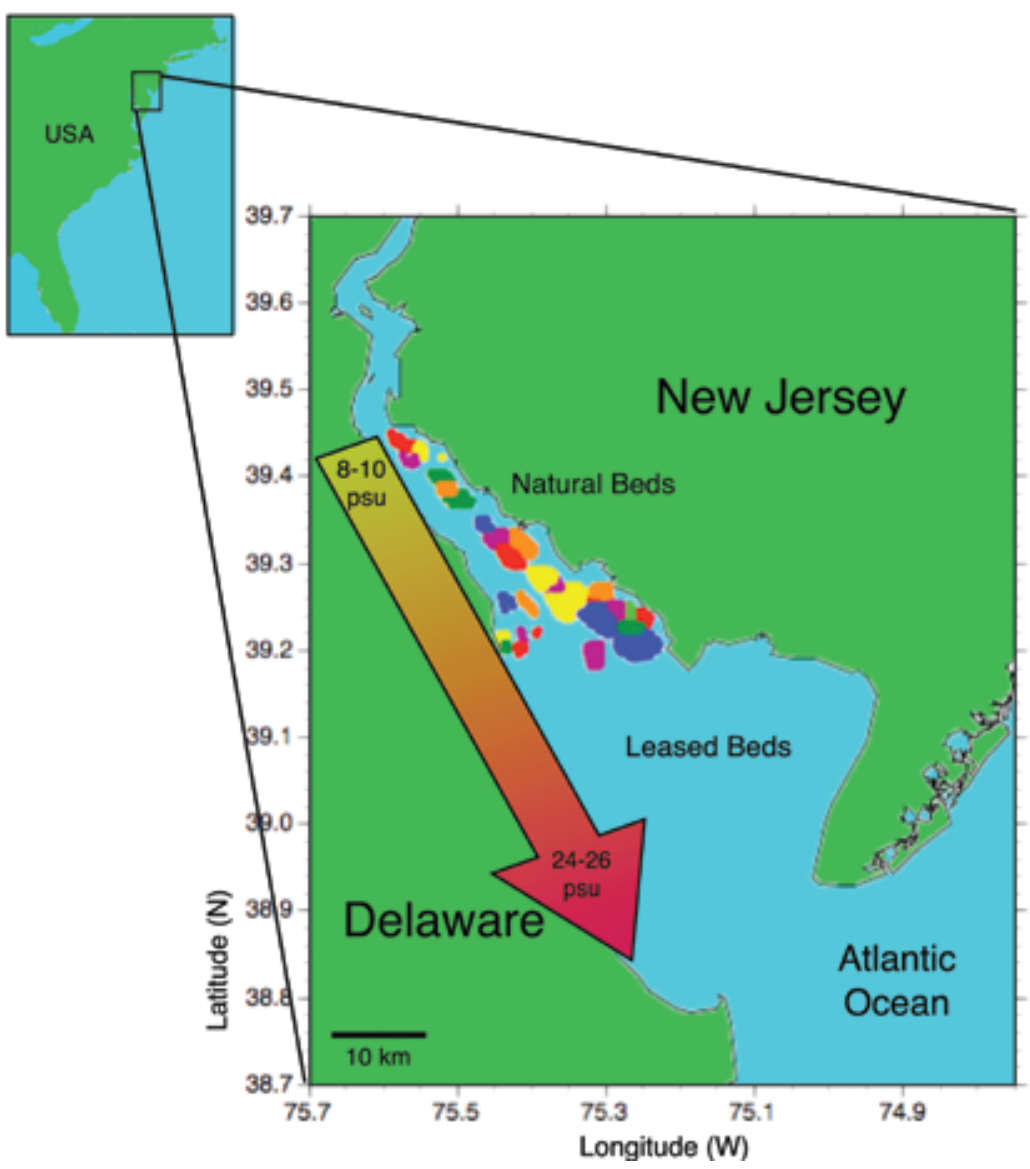

Figure 2. Map of Delaware Bay showing the locations of the natural oyster beds in the upper Bay. The arrow denotes both the salinity gradient over which oysters are typically found in the estuary and the relative intensity of disease pressure, which increases with salinity along that gradient. Historically, oysters were transplanted from the natural beds to the leased beds for growth and conditioning before market; however, high mortality caused by disease in the lower bay has limited this practice in recent years, and most oysters are marketed directly from the natural beds.

models are coupled with a Delaware Bay circulation model (Box 3) to test scenarios of the effects of disease transmission, larval transport, and current and future climate conditions on host population structure.

\section{MOTIVATION AND}

\section{CONCEPTUAL APPROACH}

As described above, Delaware Bay oyster populations have been challenged by MSX disease since 1957 and by Dermo disease since 1990 . Such sudden-onset disease events are well described (Lafferty et al., 2004), but the event unique to Delaware Bay that provided a natural disease-selection experiment occurred in 1984-1986. Between August 1984 and August 1985, Delaware River flow, which contributes about $60 \%$ of the freshwater input to the bay, was below the long-term mean (1913-1983) every month and averaged $<50 \%$ of the mean during the critical months of March through May, when spring freshets normally eliminate MSX 
The circulation model is based upon the Regional Ocean Modeling System (ROMS; Shchepetkin and McWilliams, 2005; Haidvogel et al., 2008; http://myroms.org) configured for the Delaware River and Estuary, and the adjacent continental shelf out approximately to the 60-m isobath. The model has subkilometer horizontal resolution over the entirety of the bay, and employs 20 bathymetry-following vertical levels. Bathymetry for the model was from the National Geophysical Data Center (NGDC) Coastal Relief model (http://www. ngdc.noaa. gov/mgg/coastal/coastal.html).

The Delaware Bay model is forced by atmospheric, riverine, and coastal tidal inputs. Air-sea fluxes are calculated using bulk formulae (Fairall et al., 2003) applied to three-hourly reanalysis air temperature, pressure, humidity, and winds obtained from the North American Regional Reanalysis (Mesinger et al., 2006). Freshwater inputs are prescribed for six rivers (Figure 7) from US Geological Survey gauge measurements. Variability in sea level and barotropic velocity at the continental shelf open boundaries is specified using tidal harmonics from a regional model (Mukai et al., 2001), employing the Flather (1976) method and assuming no mean inflow or outflow. Orlanksi-type radiation conditions determine the open boundary tracers and baroclinic velocity. All tracer advection is determined by the multidimensional positive definite advection transport (MPDATA) algorithm (Smolarkiewicz and Szmelter, 2005), which is important for accurate simulation of tracer (e.g., temperature and salinity) evolution.

Simulations are initialized at rest and with an unperturbed sea surface. The initial salinity field is vertically uniform (well mixed) and has an along-bay pattern following the climatology of Whitney and Garvine (2006, Figure 4). Lastly, the initial temperature field is taken to be everywhere constant at a seasonally appropriate value. Subsequent integration of the model simulation shows rapid (twoto three-day) adjustment away from these initial conditions.
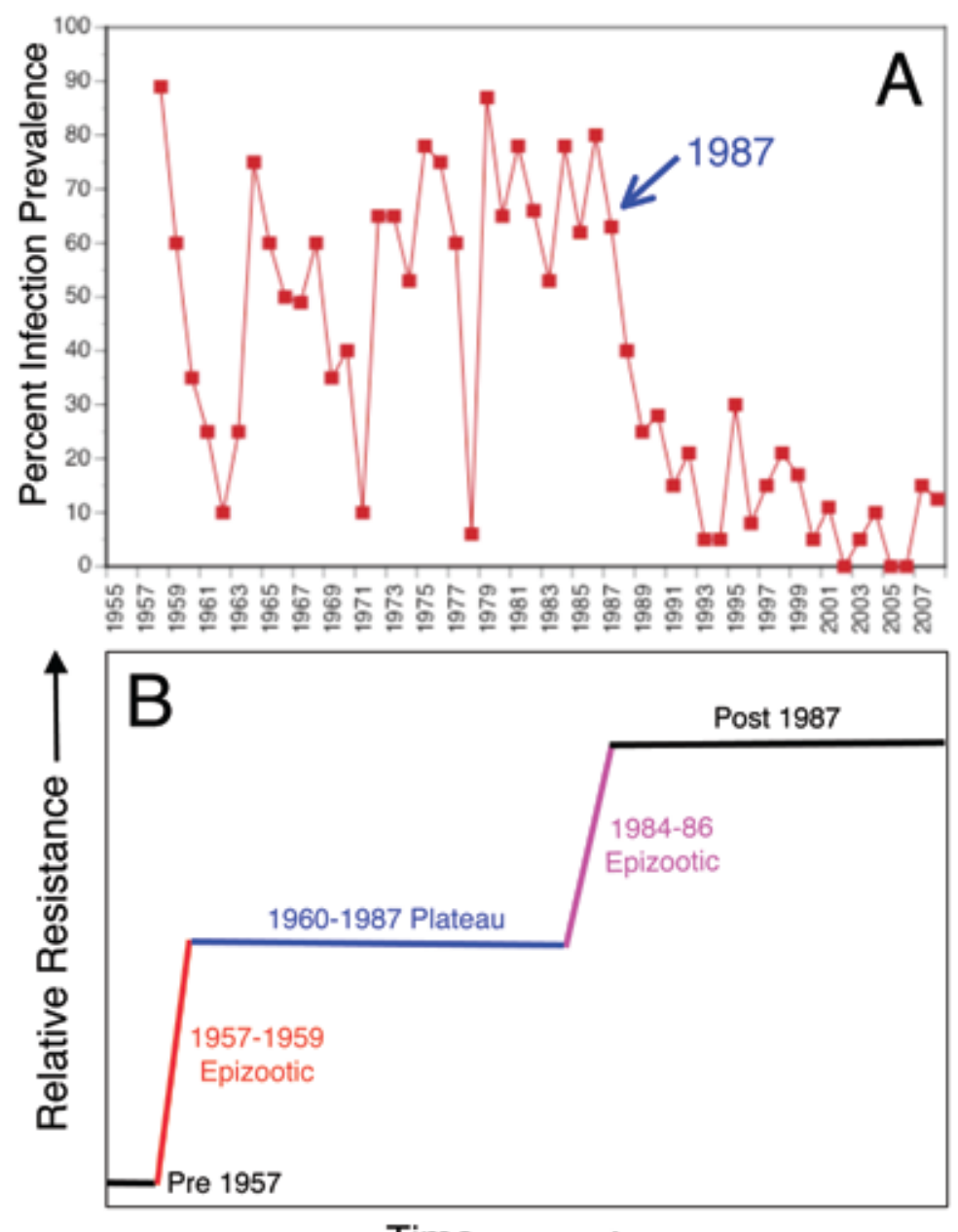

Time-
Figure 3. (A) Timeline of MSX infection prevalence in oysters in lower Delaware Bay showing the dramatic decline shortly after the 1984-1986 epizootic. (B) Conceptual diagram of the two-stage development of resistance to MSX disease in native Delaware Bay oysters. Note that after the 1957-1959 epizootic, mortality declined, but prevalence remained high except during brief periods associated with cold winters. It was not until after the second epizootic that prevalence also declined. Data to construct the timeline of MSX infection (panel A) are from the long-term records of the Rutgers University Haskin Shellfish Research Laboratory on the Delaware Bay oyster population.

from oysters in the upper bay (Haskin and Ford, 1982). At this time, MSX, which was particularly prevalent in the lower bay (Figure 3A), spread into the upper bay. By the end of 1986, it had caused $70-75 \%$ mortality of the oysters in what had been a low-salinity disease refuge. After this drought-associated epizootic, MSX disease prevalence fell dramatically (Figure 3A) and has never regained its preeminence in population control, yet oysters with no history of selection by MSX disease continue to become heavily infected and experience high mortality when exposed in the bay. 
Although some resistance had developed in the native stock after the initial epizootic in 1957-1959 (Figure 3B), it did not measurably improve thereafter, probably because the vast majority of surviving adults were in the lowsalinity refuge of the upper Delaware Bay (Haskin and Ford, 1979). Evidently, the animals that repopulated the bay after 1986 were dominated by MSX disease-resistant individuals. Was the 1984-1986 MSX-caused mortality sufficient, in itself, to remove enough susceptible oysters from the population to result in this "regime shift," or is it necessary to also invoke a sweepstakes reproductive event (see effective population size and sweepstakes reproductive success definitions in Box 1) in which only a small fraction of the survivorsthe most highly selected ones-were reproductively successful? The Delaware Bay oyster data, which document a major increment in genetic resistance that led to the functional extinction of a disease, provide a unique opportunity to explore these questions.

The Delaware Bay oyster population is structured by the along-bay salinity gradient that ranges, at mid-tide and mean Delaware River flow, from about 8-10 at the uppermost bed to about 26 in the lower bay (Figure 2). Population characteristics generally increase or decrease along this gradient with salinity and food as dominant controls. Oyster growth and fecundity are enhanced in the higher-salinity regions; however, these regions are the ones that the disease-causing parasites also find most favorable, and this decreases oyster survival. In the low-salinity regions, oyster growth and fecundity are reduced, but the ability of the parasites to survive and proliferate is compromised and oyster survival increases.

Disease refugia likely occur in lowsalinity regions. In these areas, disease selection pressure is low, permitting susceptible oysters to persist. The spatial dimension of these low-salinity regions fluctuates seasonally and with longerterm climate variation. Moreover, variations in the timing of environmental changes are important. For instance, variation in summer temperature has less effect on Dermo disease outbreaks than does change in winter temperature (Cook et al., 1998). The result is that disease selection pressure varies over space and time. Long-term stock assessment studies indicate that the Delaware Bay oyster population expands and contracts from a core in the central region (Powell et al., 2008), but it is not clear how reproductive success varies over space and time. The likelihood of interaction of gametes from any two oysters decreases with distance, but planktonic larval dispersal over two to three weeks, the average lifespan of an oyster larva, facilitates population mixing among generations, limiting the formation of subpopulations. Further, the number of parents successfully contributing to any one generation likely varies temporally along with regional contributions.

Given this conceptual model, the first effort in the EID project was to identify potential disease refugia in the lowsalinity regions of the upper Delaware Bay and its tributary rivers, and, assuming these regions exist, to identify possible phenotypic and genotypic differences in oysters from these regions and from those in high-disease areas of the lower bay.

\section{THE REFUGIA ISSUE}

Several sites in rivers and the upper Delaware Bay (Figure 4A) where oysters are present were selected as potential disease refugia (Box 4). Adult oysters were collected from these sites, as well as high-disease sites, spawned in the hatchery, and their offspring exposed to both MSX and Dermo parasites in common garden field experiments (Box 1) at two locations. At one location, the MSX parasite, but not the Dermo parasite, is prevalent (Figure 4A). Both parasites are prevalent at the other location. Infection prevalence and intensity and mortality are being assessed as measures of phenotypic differences in resistance.

A second aspect of the study is to understand the mechanisms that prevent selection and allow susceptible oysters to survive in putative refugia. Is it because low salinity prevents the parasite from developing lethal infections or is it because the parasite is simply not present in the refuge? We are comparing traditional histological and culturebased diagnostic methods with sensitive molecular assays to help differentiate between these two possibilities. If we find that the molecular assays are positive but traditional methods show no evidence of infections, or perhaps only very light infections, we can infer that the parasite is present in the refuge, but that it is not able to develop infections. If we obtain negative results from both types of assays, we can infer that the refuge exists because the parasite is not present or not sufficiently abundant to be detected by even very sensitive assays.

The surveys for parasite presence versus infection development showed that refugia are structured by both 


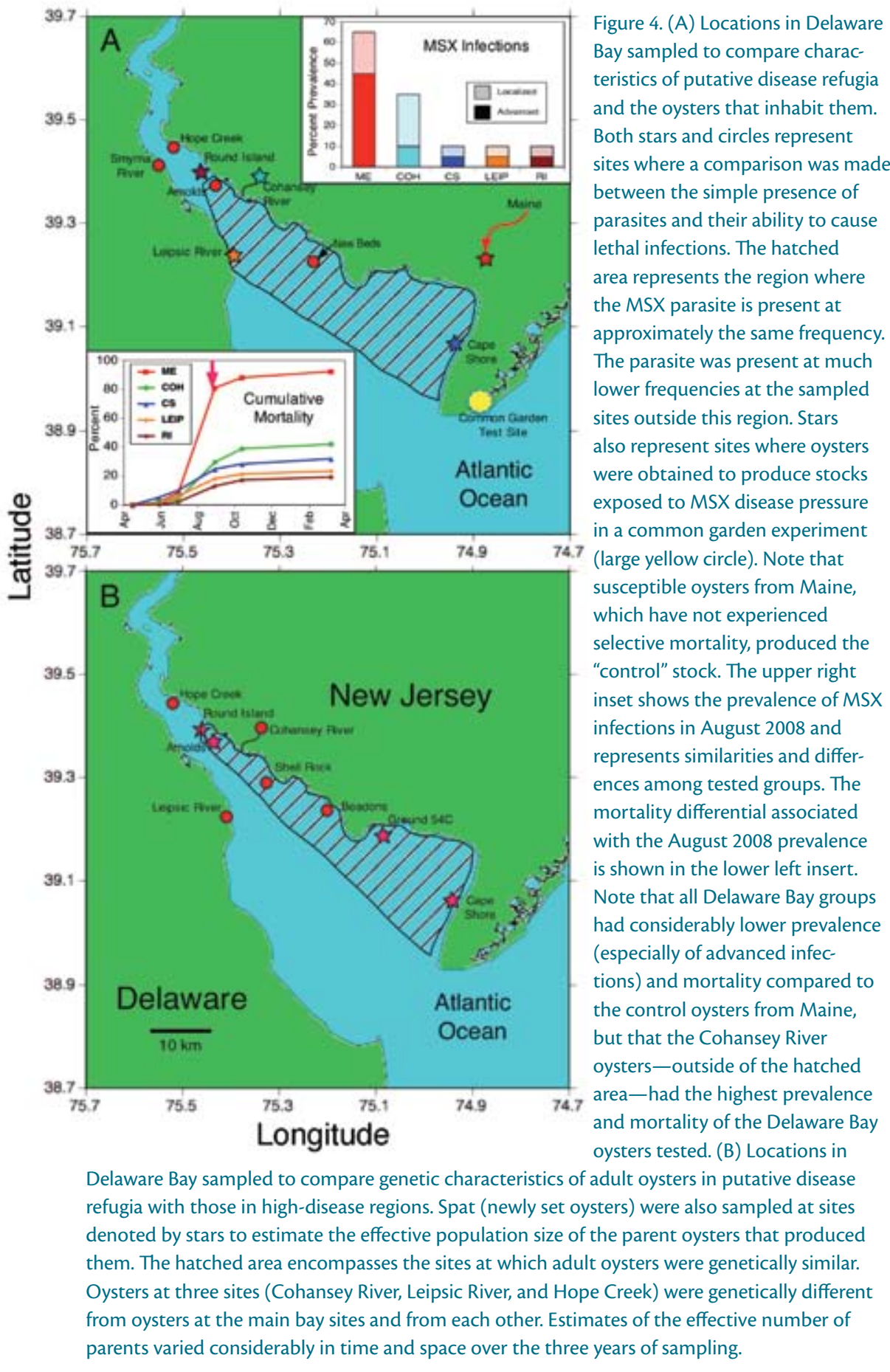

factors. In most months, we found little evidence that the MSX parasite was present at the uppermost sites (Hope Creek and Round Island beds and the Cohansey River, Figure 4A). At some sampling times during dry periods, however, we did find both molecular and histological evidence of the parasite in these locations, but no lethal-level infections. In contrast, the Dermo parasite was prevalent in all sites in both molecular and culture-based assays, although somewhat fewer lethal infections developed in the putative refugia.

Preliminary results of the common garden experiment indicate that offspring of oysters from the main portion of Delaware Bay-from Round Island Bed to Cape Shore-experienced similar mortality rates and very low infection levels when challenged by the MSX parasite (Figure 4A, insets). Offspring of oysters from the Cohansey River site had significantly higher infection and mortality, but all Delaware Bay oysters were much more resistant than offspring of control oysters from Maine, which had no history of selection by MSX (Figure 4A, insets). Dermo disease levels of groups exposed to that parasite also were similar among all Delaware Bay groups, including the Cohansey River oysters.

\section{GENOTYPIC DIFFERENTIATION IN DISEASE RESISTANCE}

The potential existence of disease refugia in upper Delaware Bay, contrasting with the strong selection pressure on oysters in lower Delaware Bay, raises three important questions about population genetic characteristics. First, does selection by the diseases cause genotypic changes in oysters that can be identified? Second, if genotypic changes do occur, has natural selection by disease-caused mortality resulted in genotypic differentiation of Delaware Bay oyster populations? Third, can we understand and predict genotypic changes with models that incorporate environmental factors and climate changes? Answers to these questions require a good understanding of the genetic basis of disease resistance. One component of the Delaware Bay EID program is designed to identify and 
Salinity is known to modulate the prevalence of infection by both MSX and Dermo parasites. Because the MSX parasite is highly sensitive to low salinity, histologically detectable infections are rarely found in oysters at salinities of 10 or less, and salinities of 15 inhibit the development of lethal infections. The Dermo parasite is much more tolerant of reduced salinity and can persist at salinities as low as 3 (Chu et al., 1993), although low salinity reduces the number of lethal infections. Before the 1984-1986 selection event, the prevalence of MSX showed a gradual reduction from high to low salinity (Figure B4-1). The prevalence of Dermo infections instead remains elevated until the average salinity is below 12 , when it abruptly decreases (Figure B4-1). Thus, refuges from selection by the two diseases in Delaware Bay are likely to be spatially different. Sampling sites chosen to document the existence of refugia and to investigate how they are maintained were based on historical disease prevalence and mortality data on major oyster beds and presumed refuge status of beds several miles upriver in tributary rivers supplying the upper Bay. These putative refugia were compared with sites in the lower Delaware Bay known to experience high disease pressure on a continuing basis.

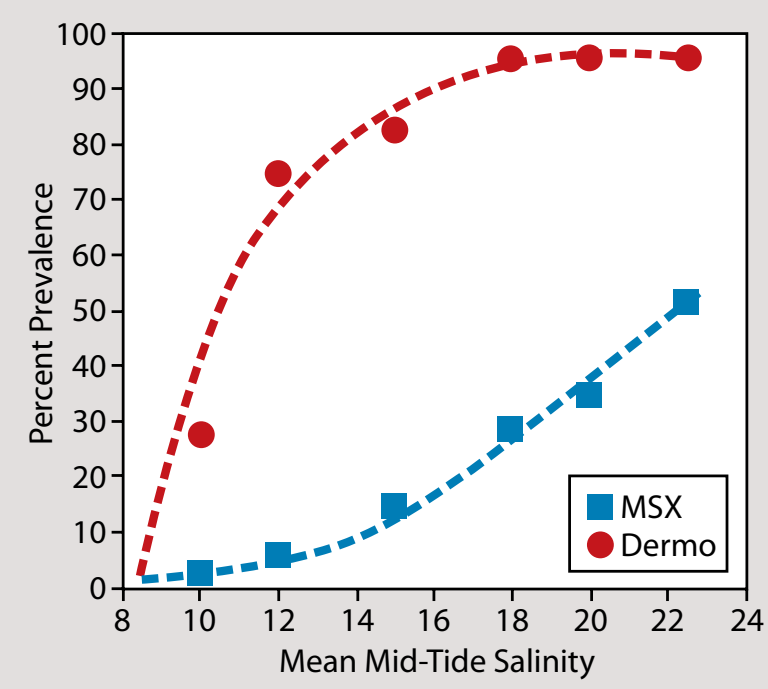

Figure B4-1. Long-term mean prevalence of MSX (1958-1980) and Dermo (1990-2005) diseases along a salinity gradient in Delaware Bay. The figure was constructed using data from the long-term records of the Rutgers University Haskin Shellfish Research Laboratory on Delaware Bay oyster populations. map disease-resistance genes/markers, and to determine their frequency distribution in Delaware Bay oysters from different sites.

Disease-resistance markers were identified based on their association with resistance phenotypes using two approaches. First, a family-based association study was conducted with hatcheryproduced oysters to identify markers that show significant frequency shifts after disease-caused mortalities (Yu and Guo, 2006). Disease-resistant (R) and susceptible (S) strains were crossed to produce F1 hybrids (RS), which were subsequently used for making backcross (RS x SS) and F2 (RS x RS) hybrid families so that disease-resistance genes were segregating in the progeny. The families were then deployed in the field, where they were exposed to MSX and Dermo parasites. These oysters were sampled before and after disease-caused mortalities and genotyped at hundreds of genetic markers (Wang and Guo, 2008). Markers that showed significant frequency shifts were identified and positioned on genetic linkage maps.

The genetic markers that showed significant frequency shifts after diseaseinflicted mortalities were closely linked to each other and formed clusters on the genetic linkage maps (Figure 5). The clustering of affected markers suggests that the frequency shifts are not random but caused by linkage to common disease-resistance genes. Therefore, affected markers in each cluster are considered disease-resistance markers that identify a region where a diseaseresistance gene resides. In one of the families studied, 24 clusters of diseaseresistance markers were found on 10 chromosomes (recent work of authors Wang and Guo).

Field mortalities of oysters can be

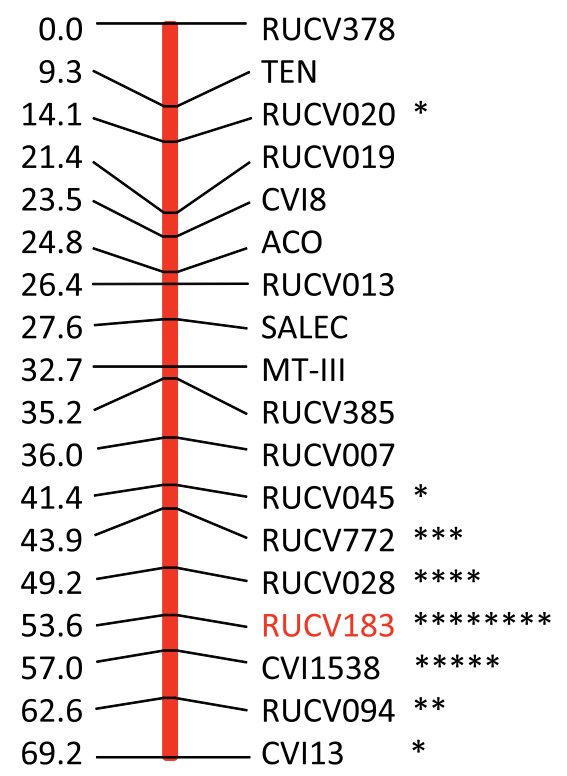

Figure 5. Identification of disease-resistance DNA markers in the eastern oyster through family-based association mapping. Markers are listed on the right of the chromosome, and genetic distances ( $C M$ ) are on the left. Markers showing significant post-mortality shifts in genotype frequency are indicated with asterisks, ranging from one for $\mathrm{p}<0.05$ to eight for $\mathrm{p}<0.00001$. RUCV183, a microsatellite derived from expressed sequence tags, in the center of the cluster is a marker closely linked to a disease-resistance gene. 
caused by factors other than Dermo and MSX diseases. Resistance markers identified based on field exposure are not disease-specific, and additional experiments were designed to determine association with specific diseases. In this second approach, a family of oysters was experimentally injected with the Dermo parasite Perkinsus marinus. The measured time to death, infection intensity, and an index incorporating both were used to map quantitative trait loci (QTLs, Box 1) conferring Dermo resistance. Mapping analysis identified five QTLs related to Dermo resistance and, as expected, some matched to the resistance markers identified with family-based association studies (Zhang et al., 2008).

Finally, a set of 23 microsatellite DNA markers that showed strong, weak, or no known linkage to disease-resistance genes was selected for population studies. Oysters were collected from nine locations in Delaware Bay (Figure 4B), including high-disease regions and presumed refugia. Genotypes of oysters from each location were determined, and genetic analyses showed significant $(\mathrm{p}<0.001)$ genetic differentiation among the nine locations. Most of the differences were found between the main body of the bay and peripheral locations, including the northernmost Hope Creek site and two tributaries (Leipsic River, Cohansey River; Milbury et al., 2008). Oysters in the main area of Delaware Bay, from Cape Shore in the lower bay to Arnolds Bed in the upper bay, are genetically homogenous (Figure 4B). These results indicate that much of the main area of Delaware Bay is genetically well mixed and that the upper bay and tributaries are genetically different from the main stem of the bay and from each other, indicating that they may be selfrecruiting areas.

Not all markers contributed equally to the observed genetic heterogeneity in Delaware Bay. Among the 23 markers, 13 showed strong $(\mathrm{p}<0.01)$ association with disease-resistance genes in a family, and the other 10 showed relatively weak or no ( $\mathrm{p}>0.01)$ apparent associations. Ten of the 13 markers that are closely linked to disease-resistance genes showed significant $(\mathrm{p}<0.05)$ population differentiation, meaning that the frequencies of alleles at these markers differed spatially. In contrast, only one of the 10 markers without close linkage to disease-resistance genes showed significant $(\mathrm{p}<0.05)$ spatial differentiation. At $\mathrm{p}<0.01$, spatial differentiation was observed at seven loci, and all seven were strongly $(\mathrm{p}<0.01)$ associated with disease-resistance genes. These findings suggest that markers with the strongest linkage to disease-resistance genes contributed more to the observed genetic differentiation than markers with weak or no association with disease-resistance genes, and disease-resistance genes may play a role in genetic differentiation of oysters in Delaware Bay. We note that the disease-resistance markers were identified from families where linkage over a large distance can be easily detected. The strength of the association may vary among families and be weakened in natural populations. Also, the findings are based on one-time sampling, and the hypothesis that disease-resistance genes have significantly contributed to population differentiation in Delaware Bay should be rigorously tested with additional sampling and more widely validated markers.

\section{EFFECTIVE POPULATION SIZE}

Effective population size is an important factor affecting the genetic differentiation of populations. A large effective population size produces low genetic drift and increases genetic stability of the population over time. Conversely, a small effective population size may allow rapid differentiation of the population. It has been hypothesized that oyster populations, despite their large census sizes, have relatively small effective population sizes, owing to large variance in individual reproductive success, and that they are prone to genetic shifts (Hedgecock et al., 1992; Hedgecock, 1994). This hypothesis of sweepstakes reproductive success, if true, has important implications for the oyster population structure in Delaware Bay. One prediction of the hypothesis is that a cohort of new recruits may have a genetic profile suggesting that it has come from a small effective number of parents $\left(N_{b}\right.$, Box 1$)$.

The effective number of parents was estimated for spat (newly settled oysters) collected at four sites in Delaware Bay (Figure 4B) in 2005, 2006, and 2007 using eight microsatellite DNA markers. The eight markers were selected from eight different chromosomes and showed no or only weak $(\mathrm{p}>0.01)$ linkage to disease-resistance genes. Preliminary results indicated that the effective number of parents for a given collection was small (72-1285) compared to the estimated (as of October 2008) census population of oysters on the New Jersey side of Delaware Bay (1.6 billion). The effective number of parents, $N_{b}$, is variable among sites and years, but in the same range (535-1517) as previously reported for the James River in 
The NSF Biocomplexity in the Environment, Genomically Enabled Environmental Science initiative provided funding to develop an individual-based genetics model for oysters as part of a research program focused on genomic approaches to understanding recruitment success. This model (Hedgecock et al., 2008) couples genetic structure to physiology, and ultimately to population dynamics, and consists of modules that simulate mortality and reproduction of the post-settlement oyster population, mortality during the planktonic larva phase, and the genetic structure of individual animals.

The genetics component of the model is based on 10 pairs of chromosomes (the number of chromosomes in the oyster), each having a selection of genes with multiple alleles. The population is described by the allelic structure of each individual and simulates the fate of individual genotypes. The genetic structure of a new individual is acquired from its parents and is modified by mutations and chromosome crossovers.

Matings produce offspring of mixed allelic structure determined by the chance pairing of female and male-derived chromosomes, modulated by crossing over. A mutation rate is based on the number of cell doublings required to reach spawning from a set of primordial germ cells. The success of any fertilized egg is based on: (1) chance of death, independent of genotype, (2) death due to lethal mutations, and ( 3 ) the presence of alleles that increase the likelihood of survival. Alleles are created by mutation and lost by genetic drift. Some alleles increase in frequency due to positive influences on fitness; others decrease in frequency due to negative influences on fitness. The gene-based model was developed using data sets collected for Crassostrea gigas.

The genetics model successfully simulates the fraction of genes carrying "lethal" alleles (high for highly fecund organisms, such as oysters), sweepstakes reproductive success, the anticipated trends in effective population size, allele loss through drift, and variation in heterozygosity for neutral alleles (Hedgecock et al., 2008).

Configuration of the model to reflect the distribution of diseaseresistant genes can be used to estimate the rate of increase in disease resistance given a rate of disease-caused mortality. The model can be used to estimate the potential of hatchery-based seed or introduction of adults with particular traits to move the population genotype toward increased disease resistance. Coupling to a hydrodynamic model allows investigation of the interaction of larval import rate and location in establishing disease-resistant genotypes to enhance oyster revitalization efforts.
Chesapeake Bay (Rose et al., 2006). At Cape Shore, spat collected early and late during the same recruitment season (2007) gave different estimates of $N_{b}$, with the late collection giving $60 \%$ higher values. Genetic analysis also indicates that spat collected from different sites and at different times are often genetically different from each other. This finding is interesting considering the adult populations from the main area of Delaware Bay are genetically homogeneous. Individual spat settlements originating from small numbers of parents are more variable than adult populations, which are stable and relatively homogenous because they are accumulations of many individual spat settlements. Longer-term studies are needed to understand and quantify the relationship between $N_{b}$ of individual cohorts and the effective size of the whole population, and whether genetic drift modulates response to selection for disease resistance.

\section{INTEGRATING GENETIC AND POPULATION PROCESSES}

Synthesis and integration of the diverse array of data collected in Delaware Bay are being done with models that simulate growth and development of larval and post-settlement eastern oyster populations, and that are coupled with models that simulate development of MSX and Dermo diseases. These models are in turn coupled with an individual-based genetics model (Box 5) that provides a unique capability of combining the genetic composition of individuals with dynamics at the subpopulation and population level. This modeling framework provides an approach to evaluating how MSX and Dermo diseases influence not only population dynamics but also the underlying genetic structure of the oyster, and to understanding the host-pathogen relationship in a changing environment.

The oyster genetics model is based on individuals with explicitly coded alleles in various locations on a genetic linkage map. Individual oysters have 10 chromosome pairs (the number that can be observed in dividing cells), with multiple genes per chromosome and multiple alleles per locus. Coupling 
of genetics and larval growth models (e.g., Bochenek et al., 2001) allows mapping of physiological function to specific alleles and genotypes and thus a mechanistic understanding of endogenous genetic and physiological factors affecting recruitment success. Adults produce larvae with specific genotypes, following Mendelian inheritance, and with prescribed relative fitness. The larval growth model predicts the likelihood of survival for individual genotypes based on the local environment.

This coupled model is being used to investigate variability in genetic composition of Delaware Bay oysters that arises from immigration (episodic and continuous) of individuals with different genotypes and effective population size (random genetic drift) as part of the effort to understand the processes that promote development of disease resistance. Simulations were designed in which new individuals, with a genetic structure that included an allele that conferred a beneficial trait, such as disease resistance, were added to the population at varying rates and over varying time spans. The effect of acquiring this allele was an increase in maximum lifetime. The question, then, is: how long does it take for the trait conferred by the allele to be the common genetic character for the population?

To evaluate how many immigrants need to be introduced, and over what time interval, to produce a genetic shift in the population, a series of simulations was done with the oyster genetics model, in which one of the genes in the second chromosome pair of individual oysters was assumed to have a particular beneficial trait (i.e., an incremental increase in life span beyond an average of five years), and its frequency in the population was tracked. The elapsed time from the introduction until the frequency of the new allele reached $25 \%$ and $50 \%$ was estimated for each simulation. The simulations were done for continuous and episodic immigration of either larval or adult oysters. The larval simulations represent inputs from spat that settle from the plankton. The adult simulations represent the effects of transplanting oysters. Simulations in which no benefit resulted to individuals that acquired the new allele provided the neutral response of the population and a baseline for comparison with the beneficial-trait (incremental increase in life span) simulations.

Overall, the time needed to introduce a new trait decreased as the number of immigrants increased (Figure 6). The lower limit for introduction of a trait that becomes established in $25 \%$ or $50 \%$ of the population that initially consisted of 800,000 individuals was about 5,000 individuals $(0.5 \%$ of the initial population). Introduction in excess of 50,000 individuals resulted in the allele frequency of the new trait reaching $25 \%$ in just five years (Figure $6 \mathrm{~A}, \mathrm{~B}$ ) and $50 \%$ in about $10-15$ years (Figure 6C,D). Continuous immigration tended to establish the introduced allele faster, especially for low-immigrant number
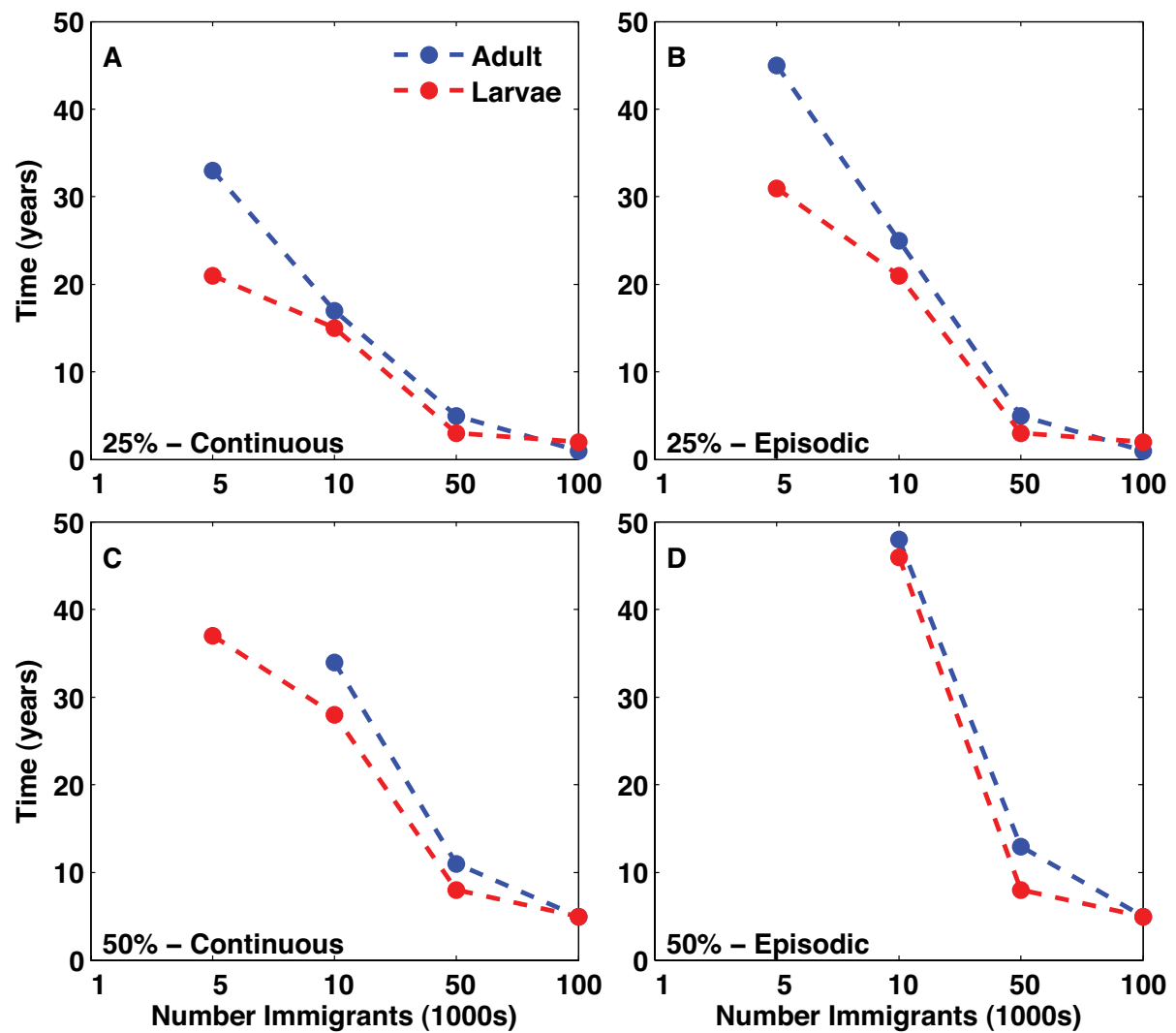

Figure 6. Time from introduction of new immigrants with a particular beneficial allele to establishment of the allele at a $25 \%(A, B)$ and $50 \%(C, D)$ level in the population for continuous and episodic immigrations. New individuals are introduced as transplanted adult oysters (blue line) or as oyster larvae (red line). 
inputs (Figure 6A,C). Introductions of individuals for limited time periods required about 10 years more for a new trait to become established (Figure 6B,D). The frequency of the beneficial trait increased when immigrants were added over a long time and when large numbers of individuals were added (Figure 6).

An interesting result of the simulations is that the increase in frequency of a new trait is more rapid if it is introduced via larvae (Figure 6). Larval immigrants decrease the time needed for the allele to become established in the population, both for continuous and episodic immigrations, and this time factor is independent of the number of new individuals added to the population. These results suggest that larvae that survive to set (i.e., those remaining after planktonic larval mortality) are more successful in the transfer of new traits into a population than the introduction via adults transplanted from other regions, with presumably different genetic characteristics. This counterintuitive result arises from the age-dependent mortality, which is higher for older animals, that is imposed on the simulated oyster population. The adults have shorter lifetimes and hence have fewer opportunities to reproduce compared to young (i.e., newly settled larvae). Higher mortality of younger oysters would potentially allow older adults with a particular trait in the spawning population to spread the allele faster. Thus, understanding population mortality processes is an important component of understanding how new genetic traits are introduced into populations.
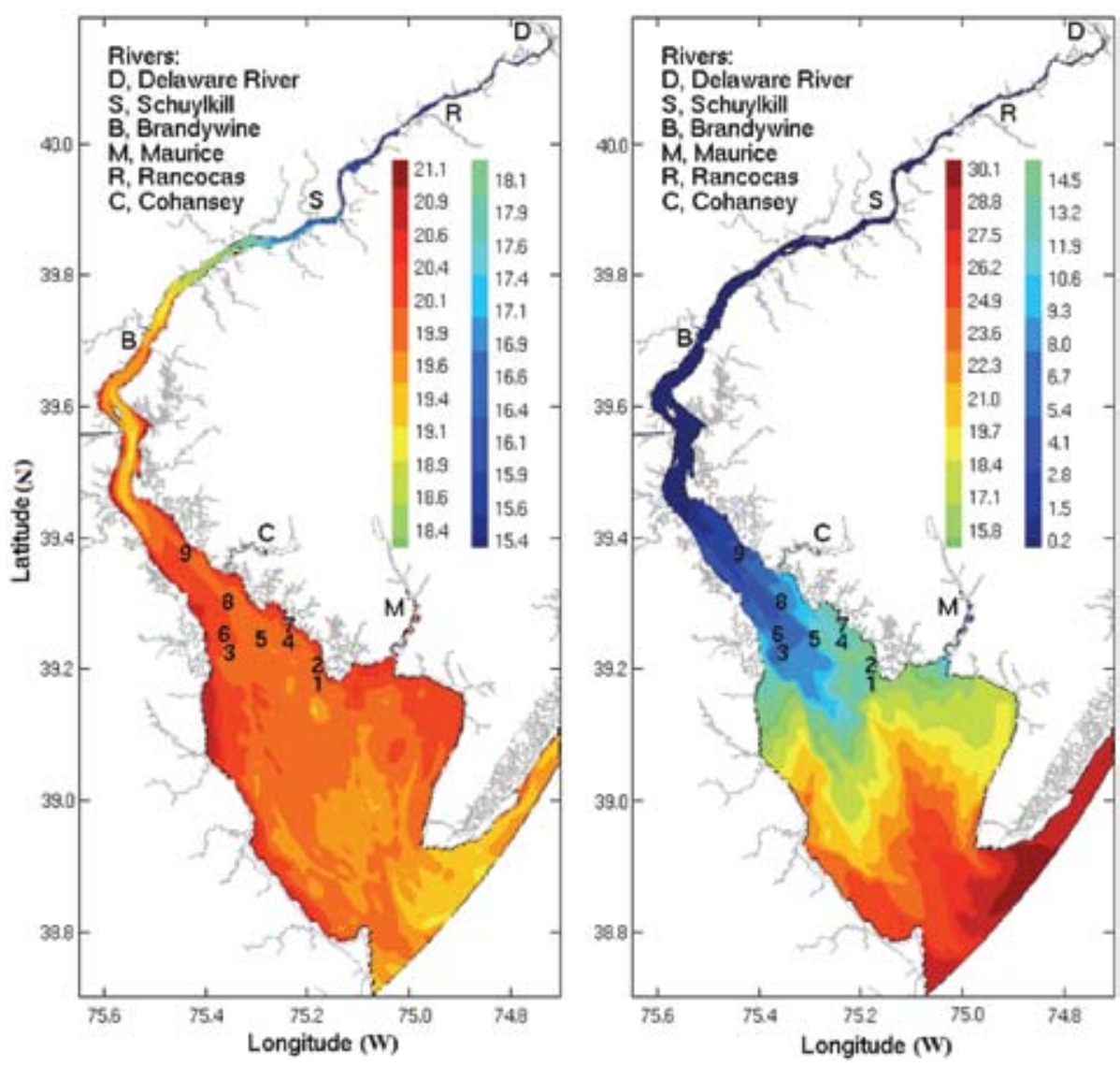

Figure 7. Surface temperature (left panel, ${ }^{\circ} \mathrm{C}$ ) and salinity (right panel, PSU) on May 25, 2000, as simulated by the Delaware Bay model. The locations of the six rivers that provide freshwater inputs for the Delaware Bay circulation model are indicated. The locations of the Versar data stations used for the quantitative comparisons shown in Figure 8 are indicated by the numbers.

\section{THE DELAWARE BAY}

\section{CIRCULATION MODEL}

The Delaware River estuary is a weakly stratified to well-mixed system in which tidal forcing predominates over the influence of freshwater input and winds. The salinity field is observed to vary systematically along-estuary (Figure 2), with values in the upper estuary ranging from 0 to 3, increasing down-estuary to 29 to 30 near the bay's mouth. The lower estuary displays transient salinity stratification, generally strongest following maximum river discharge in the spring (Garvine et al., 1992). Few long-term mooring deployments have been conducted in the Delaware River estuary and, consequently, a detailed picture of the structure of its estuarine circulation is lacking. Based on limited surface drifter data, Wong (1994) suggested that the flow is laterally sheared; however, MacCready (2004) showed that a simple two-layer exchange model accurately captures the structure of the salt field.

Realistic simulation of the circulation and (importantly) the tracer fields in Delaware Bay is an essential objective of the Delaware Bay EID program. Accordingly, validation and improvement of a circulation model (Box 3 ) have been an integral and ongoing component of 
the EID project. For purposes of model evaluation, hindcast simulations of Delaware Bay circulation, and the accompanying temperature and salinity fields, have been performed covering three time periods (1984-1985, 2000-2001, and 2005) for which high-quality observational data records could be obtained. The 2000-2001 period is particularly attractive for evaluation of the circulation model because water-level records are available at 15 sites around Delaware Bay and nearly year-long observational records of temperature and salinity are available at nine locations over the primary oyster beds (Figure 7). The latter data sets were obtained as part of a water-quality and oyster-bed monitoring program intended to provide baseline information prior to a planned deepening of the Delaware Bay navigational channel
(Versar, 2001). For purposes of model evaluation, a hindcast simulation was performed for the first eight months of the temperature and salinity time series.

Delaware Bay is a tidally driven estuary; hence, correct representation of the tidal currents provides an important measure of simulated circulation. Comparison of the amplitude and phase of the observed and predicted principal lunar semi-diurnal $\left(\mathrm{M}_{2}\right)$ tidal constituent shows good quantitative agreement with observed water levels in 2000 with root mean square (RMS) errors of order of $13 \mathrm{~cm}$ in amplitude and 12 degrees in phase. The properties of the $\mathrm{M}_{2}$ tide are well represented throughout the model domain.

The simulated temperature and salinity fields display substantial variability on tidal, diurnal, and seasonal time scales; Figure 7 shows examples of surface tracer distributions. In general, salinity patterns and variability are locally forced, predominantly by the tides. The temperature patterns, while also responding to tidal forcing, have much more evident diurnal and seasonal components.

Quantitative assessment of the simulated temperature and salinity fields at the nine mooring sites was done using Taylor diagrams (Taylor, 2001), in which the normalized standard deviation, the crosscorrelation, and the centered-pattern RMS difference between the observed and simulated time series are displayed simultaneously in a single diagram (Figure 8). The hindcast temperatures are highly correlated $(\sim 0.99)$ at all locations, although with a somewhat higher standard deviation than that of the observed
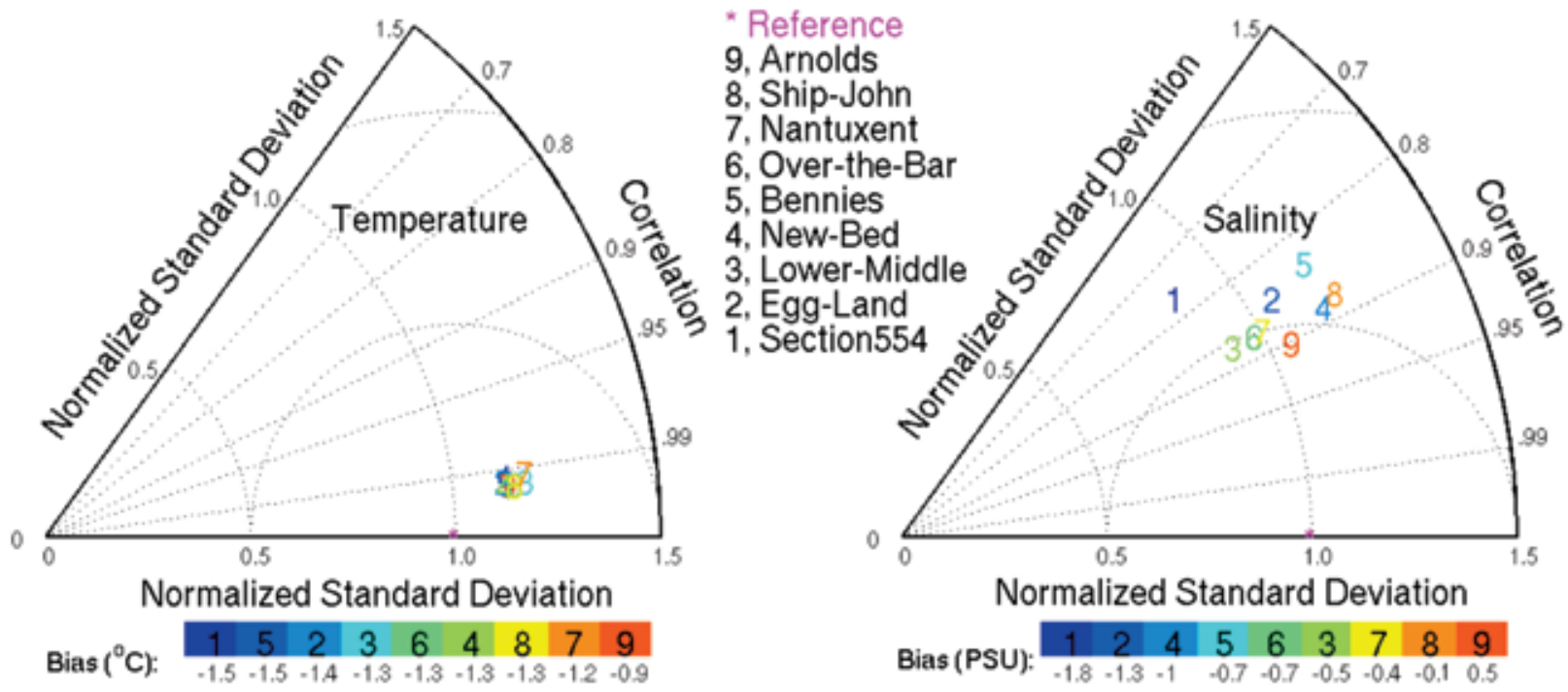

Figure 8. Taylor diagrams comparing the observed and simulated temperature (left) and salinity (right) at nine mooring locations shown in Figure 7. The observing period is May 12 through November 30, 2000. The Taylor diagram is based on calculations of the square root of mean square difference (RMSD) between the model and the data. The RMSD is composed of the bias, which is the difference between the means of the two fields and the centered-pattern RMSD, which represents differences in variability. The centered-pattern RMSD is further decomposed into differences in the phase and standard deviations of the model and observed data time series (Oke et al., 2002). The normalized standard deviation of the model result is the radial distance from the origin, the correlation of the two distributions is the angle from the $x$-axis, and normalized centered-pattern RMSD is the distance between the data symbol at location $[1,0]$ on the $\mathrm{x}$-axis (red star-reference point) and each model symbol. Bias in the simulated temperature and salinity is shown by the color bar. 
temperatures. The simulated salinities are also well correlated with observations ( 0.8-0.9), with comparable standard deviations. Some geographical variation in the quality of the salinity simulations is evident. The poorest agreement with observed salinity fields is found at the most down-bay station (location 1 , Figure 7), a possible result of the limitations of our treatment of tracers at the open coastal boundaries.

In a parallel study, model-derived currents for a two-month period in 2005 have shown general agreement with observed velocities. Hence, we have established that the Delaware Bay model can reproduce hindcasts of circulation and tracer fields that have skill, as measured by quantitative statistical measures.

\section{COUPLING OF OYSTER AND CIRCULATION DYNAMICS}

As the first step in coupling the oyster models with the Delaware Bay circulation model, Lagrangian tracking experiments were conducted using particles embedded in simulations of Delaware Bay circulation. The particles were proxies for oyster larvae. In these simulations, particle locations were tracked over time and the temperature and salinity at each location estimated. The locations of the particles were determined by horizontal and vertical advective velocities, vertical turbulence, and larval behavior and growth. Larval behavior and swimming speed are related to larval size, the local temperature and salinity, and the vertical salinity gradient (Dekshenieks et al., 1996). Oyster larvae, especially in their later stages, respond to increasing salinity by swimming up in the water column, and to decreasing salinity by falling (Haskin, 1964; Haskin and Hidu, 1978; Kennedy and van Heukelme, 1986; Mann, 1991). Particles were released at five-day intervals from mid-June to mid-September, when oyster larvae are likely to be present, at locations that correspond to known oyster beds in Delaware Bay (Figure 2). The simulated larvae grow and develop in response to local temperature, salinity, and specified food conditions using the model in Dekshenieks et al. $(1993,1997)$. The larval particles were tracked until they reached a size sufficient for metamorphosis and setting, which was about 30 days for the simulated temperature and salinity conditions and prescribed constant food distribu-

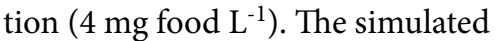
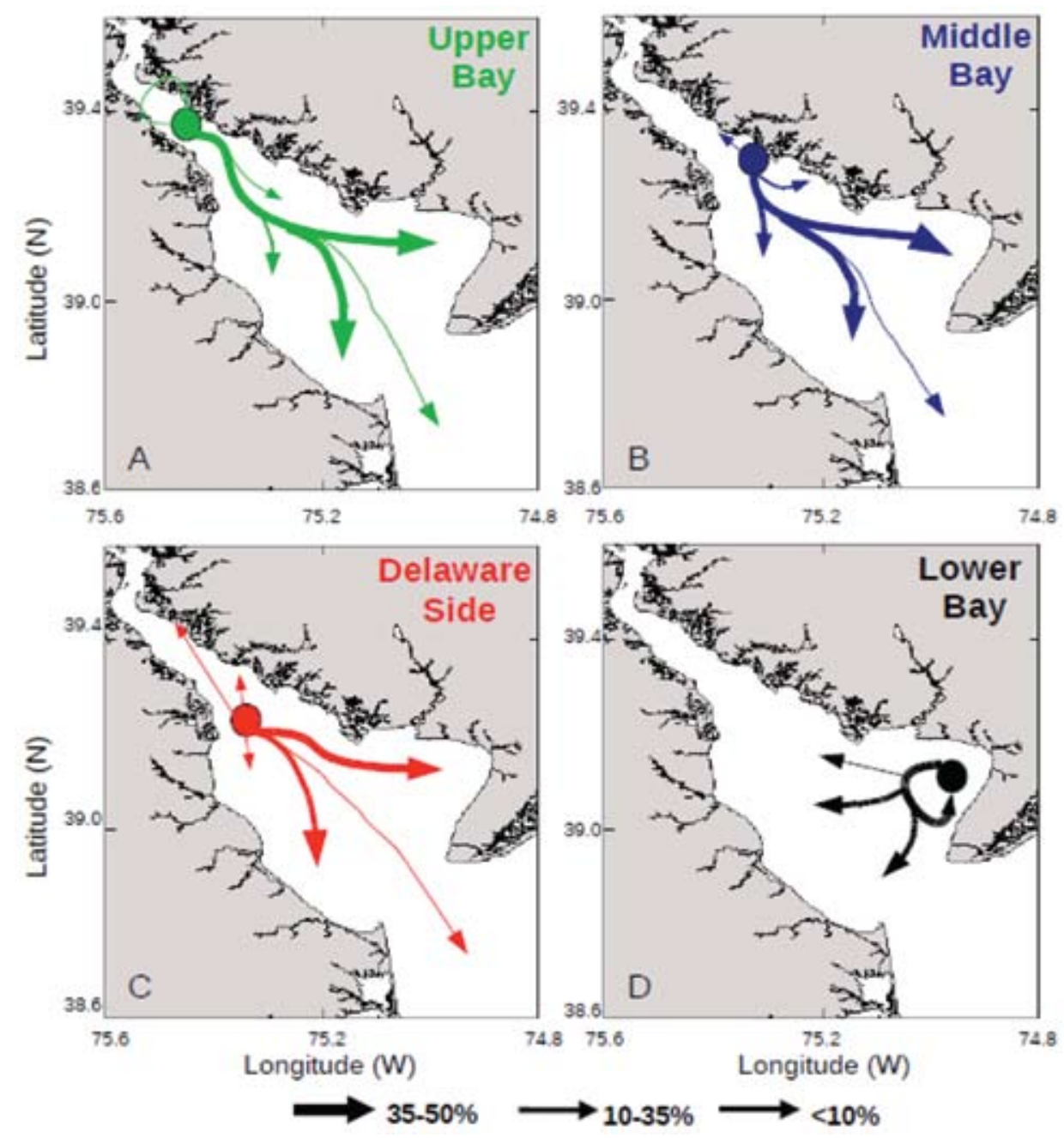

Figure 9. Summary of simulated particle transport pathways and final settlement locations for particles released between June 15 and September 15, 1984, at oyster bed locations in (A) upper Delaware Bay, New Jersey side; (B) middle bay, New Jersey side; (C) Delaware side of the bay; and (D) lower bay, New Jersey side. Arrows indicate exported particle trajectories, and the size of the arrows (see key) represents the percentage of particles released at the site that is exported to other locations in the bay. 
circulation field was obtained using conditions that correspond to 1984.

Most of the particles released in the upper Delaware Bay (35-50\%) were transported and dispersed toward the lower bay (Figure 9A). A few settled in the middle bay and fewer than $10 \%$ were exported to the adjacent continental shelf. Similar results were obtained for particles released in the middle bay (Figure 9B) and further to the west on the Delaware side (Figure 9C). Fewer than $10 \%$ of the larvae released in these locations were transported to the upper part of Delaware Bay. Particles released in the lower bay tended to remain in the region but with some export to the western and middle portions of the bay (Figure 9D). Lower bay particle transport patterns are indicative of a recirculation gyre in this part of Delaware Bay.

\section{SUMMARY AND}

\section{FUTURE DIRECTIONS}

The Delaware Bay EID project is providing data and model results that allow quantitative and rigorous evaluation of our primary hypothesis, that environmental fluctuation may combine with disease and small parental numbers to shift genotypes in unexpected ways. Addressing this hypothesis has led to understanding of how environment and disease have combined to produce the current structure of Delaware Bay oyster populations. Field surveys indicated that refuges from MSX selective pressure occurred only in the very uppermost portions of the main stem of the bay and in the tributary rivers of that region, notably the Cohansey River site. The same sites were not refuges from the Dermo parasite, which has a higher tolerance for low salinity. These observations are consistent with field studies in which offspring of oysters from putative refugia and high-disease regions were challenged by Dermo and MSX. Oysters originating from the Cohansey River experienced significantly higher MSX levels and mortality than did oysters from the other regions tested, which showed no differences among sites. No significant differences in Dermo disease levels among the same groups, including the Cohansey River, were recorded when the Dermo parasite was added to the challenge. These observations, combined with the larval model simulations, indicate that mixing of oyster larvae in Delaware Bay is extensive, but reduced in the upper bay and the tributaries. This is consistent with genetic analysis results showing that most of the oysters in the main stem of the bay are homogenous, and oysters from the far upper bay (Hope Creek) and the tributaries are genetically different. Local recruitment within a tributary may lead to genetic drift. Our data also suggest that selection by disease may also be important in causing genetic differentiation between the main stem of the bay and the refugia. The selection hypothesis is consistent with field observations of a rapid increase in resistance that was observed after the 1984-1986 MSX epizootic.

A small and variable effective number of parents was observed for different spat falls, whereas the adult populations, which represent accumulations of many year classes, may be quite stable. The role that sweepstakes reproductive events play in structuring oyster populations requires long-term analysis of the adult population and yearly recruitments. The existence of putative MSX disease refugia in the upper Delaware Bay may mean that this system is not able to develop disease-resistant oyster populations, except through large-scale catastrophic events such as the disease epizootic that occurred in 1984-1986. Thus, environmental conditions that set up such strong selection events are important in this system because one such event can radically alter the overall population structure, which then persists for several decades. Alternatively, the immigration simulations indicate that long-term sustained input of larvae and/or adults with particular advantageous characteristics will eventually result in establishment of new traits in an oyster population. This implies that management efforts that add immigrants continuously over a period of time may intentionally or unintentionally shift the genetic composition of the population.

Delaware Bay circulation is critical in the patterns of larval dispersal prior to setting and to providing a way to assess how specific genotypes are distributed within the bay. Changes in atmospheric forcing and freshwater inflow can alter bay circulation, with the consequence that the larval source regions (e.g., specific reefs or sections of the bay) change with time. Thus, the development of a particular genotype via a selection event or input of new individuals does not necessarily mean that it will be distributed to the rest of the bay or even retained in the bay. The circulation field imposes a filter on the larvae, and their associated genetic traits, which determines their ultimate fate and/or retention in Delaware Bay.

Changes in circulation due to modifications in wind fields, freshwater inputs, and bathymetry (i.e., deep channels), for 
example, have the potential to change the source and destination regions for oyster larvae. Climate change in the US Mid-Atlantic region is projected to produce warmer and wetter conditions (Najjar et al., 2000). The climate-induced changes may result in lower salinity and hence lower disease levels. However, there are trade-offs with stresses imposed on oyster physiology, as well as alterations in food supply at lower salinity, that may negate the benefit from reduced disease levels at low salinity.

A potential counter to low salinity from climate is increased salinity from deepening the Delaware Bay ship channel (see reports listed at: http:// www.nap.usace.army.mil/cenap-pl/ drmcdp/econreanal.html). Higher salinity may promote development of more oyster reef area (e.g., Powell et al., 1995), change the effects of disease mortality (Dekshenieks et al., 2000), or change the oyster population structure (Klinck et al., 2002). How these various environmental changes interact, and the consequences for Delaware Bay oyster populations, remain to be determined.

One clear result from the larval dispersion simulations is that a portion of the Delaware Bay oyster larvae population is exported to the coastal ocean, and that this portion varies with the circulation characteristics and larval source region. The exported larvae provide a mechanism for transporting particular genotypes to other systems. Thus, the selection processes that occur in Delaware Bay potentially have wider-reaching effects. For example, a southerly flowing coastal current of $10 \mathrm{~cm} \mathrm{~s}^{-1}$ could move Delaware Bay oyster larvae $200 \mathrm{~km}$ during a 20-day planktonic phase, which would be within reach of Chesapeake Bay. Additionally,
Delaware Bay likely exports water-borne disease agents, such as the MSX and Dermo parasites, along the same flow trajectories. Thus, export of larvae and parasites from Delaware Bay and the degree of exchange that occurs with the estuarine environments that connect with the coastal ocean and between large estuarine systems, such as Delaware and Chesapeake bays, can mitigate or enhance the spread of oyster diseases.

An important application of the results from studies such as this is to inform those tasked with setting policy and management procedures for living resources. For example, market forces affecting the oyster fishery, along with size restrictions on what can be harvested, place the fishing pressure on the largest ( $>2.5$ to 3 inches) and probably the oldest oysters, which are the most highly selected for disease resistance and fast growth. Removing these oysters from the population minimizes the chance for these characteristics to become instilled in the natural population. In this regard, the fishery may provide a sink for the genotypes that are desirable to retain.

Removal of individuals with traits that are potentially beneficial to the long-term survival of the natural population places a larger burden on restoration efforts. The effectiveness of small-scale repletion projects (such as those now ongoing in Chesapeake Bay) using disease-resistant oyster stocks, transplanting oysters from other regions, and importing oysters from other systems needs to be assessed in terms of the potential small effective population size, the effect of circulation variability, and possible climate change. For example, importation of infected oysters into a system where the population is already infected and lives in an environment that is favorable for establishment of the disease may not noticeably increase the likelihood of new infections. This may result in less of a long-term perturbation than continued introduction of individuals with modified genetic structure. The experimental and modeling frameworks developed in this study for Delaware Bay provide a structure for assessing these tradeoffs. However, interpreting the results to obtain evaluations of the relative importance of interactions among genetic, demographic, ecological, and environmental factors is a daunting challenge.

Moving these research-based approaches to a management arena requires a close working relationship between scientists and managers in which managers provide a clear indication of the kind of information that they need about (oyster) diseases, as well as the form in which it is most useful to them and how they intend to use it. Furthermore, to be effective, managers will need tools to simulate the consequences of various management strategies, which may require development of alternative model structures that include explicit socio-economic outcomes.

As our basic understanding of oyster disease dynamics in Delaware Bay develops, we are in a better position to recommend management strategies for this system, but major questions remain. For example, how typical is the Delaware Bay oyster disease system? Does it extend to other bays and is it applicable to other host-parasite disease dynamics in aquatic systems? How much exchange occurs among systems via coastal transport and how does that rate of exchange compare with anthropogenically assisted 
exchange (e.g., via ship hulls and ballast water or intentional transplantation of host organisms)? Is the alteration of genetic structure in one estuary likely to influence processes in another system? What is the role of hosts and parasites in smaller coastal bays and impoundments relative to larger systems such as Delaware Bay across the range of the host species? Our Delaware Bay EID project provides the tools and interdisciplinary approaches needed to answer these questions.

\section{ACKNOWLEDGEMENTS}

The Delaware Bay EID project is supported by the National Science Foundation, Ecology of Infectious Diseases Program, grant number NSF OCE 0622672. NSF REU supplements supported participation in this project by T. Evans, J. Pydeski, D. Zemeckis, J. Kauffman, K. Cheng, J. Paterno, and G. Bradbury. Additional technical, laboratory, and field assistance has been provided by I. Burt, E. Scarpa, E. Green-Beach, B. Landau, G. DeBrosse, and E. Gaine. 四

\section{REFERENCES}

Ackerman E., L.R. Elveback, and J.P. Fox. 1984. Simulation of Infectious Disease Epidemics. Charles C. Thomas, Springfield, IL, 202 pp.

Andrews, J.D. 1983. Minchinia nelsoni (MSX) infections in the James River seed-oyster area and their expulsion in spring. Estuarine, Coastal and Shelf Science 16:255-269.

Andrews, J.D., and J.L. Wood. 1967. Oyster mortality studies in Virginia. VI. History and distribution of Minchinia nelsoni, a pathogen of oysters, in Virginia. Chesapeake Science 8:1-13.

Bochenek, E.A., J.M. Klinck, E.N. Powell, and E.E. Hofmann. 2001. Biochemically based model of the growth and development of Crassostrea gigas larvae. Journal of Shellfish Research 20:243-265.

Bower, S.M., S.E. McGladdery, and I.M. Price. 1994. Synopsis of infectious diseases and parasites of commercially exploited shellfish. Annual Review of Fish Diseases 4:1-200.
Brown, B.L., A.J. Butt, S.W. Shelton, D. Meritt, and K. T. Paynter. 2005. Resistance to Dermo in eastern oysters, Crassostrea virginica (Gmelin), of North Carolina but not Chesapeake Bay heritage. Aquaculture Research 36:1,391-1,399.

Burreson, E.M., and S. Ford. 2004. A review of recent information on the Haplosporidia, with a special reference to Haplosporidium nelsoni (MSX disease). Aquatic Living Resources 17:499-517.

Burreson, E.M., and L.M. Ragone Calvo. 1996. Epizootiology of Perkinsus marinus disease of oysters in Chesapeake Bay, with emphasis on data since 1985. Journal of Shellfish Research 15:17-34.

Burreson, E.M., N.A. Stokes, and C.S. Friedman. 2000. Increased virulence in an introduced pathogen: Haplosporidium nelsoni (MSX) in the eastern oyster Crassostrea virginica. Journal of Aquatic Animal Health 12:1-8.

Bushek, D., C.F. Dugan, and A.J. Lewitus. 1994. Serological affinities of the oyster pathogen Perkinsus marinus (Apicomplexa) with some dinoflagellates (Dinophyceae). Journal of Eukaryotic Microbiology 49:11-16.

Chu, F.-L.E., J.F. La Peyre, and C.S. Burreson. 1993. Perkinsus marinus susceptibility and defenserelated activities in eastern oysters, Crassostrea virginica: Salinity effects. Journal of Invertebrate Pathology 62:226-232.

Coen, L.D., and M.W. Luckenbach. 2000. Developing success criteria and goals for evaluating oyster reef restoration: Ecological function or resource exploitation? Ecological Engineering 15:323-343.

Cook T., M. Folli, J. Klinck, S. Ford, J. Miller. 1998. The relationship between increasing sea surface temperature and the northward spread of Perkinsus marinus (Dermo) disease epizootics in oysters. Estuarine, Coastal and Shelf Science 40:587-597.

Culloty, S.C, M.A. Cronin, and M.F. Mulcahy. 2003. Possible limitations of diagnostic methods recommended for the detection of the protistan, Bonamia ostreae in the European flat oyster, Ostrea edulis. Bulletin of the European Association of Fish Pathology 23(2):67-71.

Dekshenieks, M.M., E.E. Hofmann, J.M. Klinck, and E.N. Powell. 1996. Modeling the vertical distribution of oyster larvae in response to environmental conditions. Marine Ecology Progress Series 136:97-110.

Dekshenieks, M.M., E.E. Hofmann, J.M. Klinck, and E.N. Powell. 1997. A modeling study of the effects of size- and depth-dependent predation on larval survival. Journal of Plankton Research 19:1,583-1,598.

Dekshenieks, M.M., E.E. Hofmann, J.M. Klinck, and E.N. Powell. 2000. Quantifying the effects of environmental variability on an oyster population using a coupled oyster-circulation model. Estuaries 23:593-610.

Dekshenieks, M.M., E.E. Hofmann, and E.N. Powell. 1993. Environmental effects on the development of larvae of Crassostrea virginica: A modeling study. Journal of Shellfish Research 12:241-254.
Encomio, V.G., S.M. Stickler, S.K. Allen, and F.L. Chu. 2005. Performance of "natural dermo-resistant" oyster stocks: Survival, disease, growth, condition and energy reserves. Journal of Shellfish Research 24:143-155

Fairall, C.W., E.F. Bradley, J.E. Hare, A.A. Grachev, and J.B. Edson. 2003. Bulk parameterization of air-sea fluxes: Updates and verification for the COARE algorithm. Journal of Climate 16:571-591.

Flather, R.A. 1976. A tidal model of the northwest European continental shelf. Memoirs de Société Royale des Sciences de Liège, Series 6 10:141-164.

Ford, S.E. 1996. Range extension by the oyster parasite Perkinsus marinus into the northeastern US: Response to climate change? Journal of Shellfish Research 15:45-56.

Ford, S.E., and H.H. Haskin. 1982. History and epizootiology of Haplosporidium nelsoni (MSX), an oyster pathogen in Delaware Bay, 1957-1980. Journal of Invertebrate Pathology 40:118-141.

Ford, S.E., J.N. Kraeuter, R.D. Barber, and G. Mathis. 2002. Aquaculture associated factors in QPX disease of hard clams: Density and seed source. Aquaculture 208:23-38.

Ford, S.E., E.N. Powell, J.M. Klinck, and E.E. Hofmann. 1999. Modeling the MSX parasite in eastern oyster (Crassostrea virginica) populations. I. Model development, implementation, and verification. Journal of Shellfish Research 18:475-500.

Gaffney, P.M., and D. Bushek. 1996. Genetic aspects of disease resistance in oysters. Journal of Shellfish Research 15:135-140.

Garvine, R.W., R.K. McCarthy, and K.C. Wong. 1992. The axial salinity gradient distribution in the Delaware estuary and its weak response to river discharge. Estuarine, Coastal and Shelf Science 13:157-165

Haidvogel, D.B., H. Arango, W.P. Budgell, B.D. Cornuell, E. Curchitser, E. Di Lorenzo, K. Fennel, W.R. Geyer, A.J. Hermann, L. Lanerolle, and others. 2008. Ocean forecasting in terrain-following coordinates: Formulation and skill assessment of the Regional Ocean Modeling System. Journal of Computational Physics 227:3,595-3,624

Haskin, H.H. 1964. The distribution of oyster larvae. Pp. 76-80 in Occasional Publication 2. N. Marshall, H.P. Jeffries, T.A. Napora, and J.M. Sieburth, eds, Symposium on Experimental Marine Ecology, Graduate School of Oceanography, University of Rhode Island.

Haskin, H.H., and S.E. Ford. 1979. Development of resistance to Minchinia nelsoni (MSX) mortality in laboratory-reared and native oyster stocks in Delaware Bay. US National Marine Fisheries Service. Marine Fisheries Review 41:54-63.

Haskin, H.H., and S.E. Ford. 1982. Haplosporidium nelsoni (MSX) on Delaware Bay seed oyster beds: A host-parasite relationship along a salinity gradient. Journal of Invertebrate Pathology 40:388-405. 
Haskin, H., and H.H. Hidu. 1978. Swimming speeds of oyster larvae Crassostrea virginica in different salinities and temperatures. Estuaries 1:252-255.

Haskin, H.H., L.A. Stauber, and J.A. Mackin. 1966. Minchinia nelsoni n. sp. (Haplosporida, Haplosporidiidae): Causative agent of the Delaware Bay oyster epizootic. Science 153:1,414-1,416.

Hedgecock, D. 1994. Does variability in reproductive success limit effective population sizes of marine organisms? Pp. 122-134 in Genetics and Evolution of Aquatic Organisms. A. Beaumont, ed., Chapman \& Hall, London.

Hedgecock, D., V. Chow, and R.S. Waples. 1992. Effective population numbers of shellfish broodstocks estimated from the temporal variance in allelic frequencies. Aquaculture 108:215-232.

Hedgecock, D., J.M. Klinck, E.N. Powell, L. Plough, and E. Hofmann. 2008. Insights into oyster population genetics from an Individual Based Model. Journal of Shellfish Research 27:1015. (abstract)

Hofmann, E.E., E.N. Powell, J.M. Klinck, and G. Saunders. 1995. Modeling diseased oyster populations. I. Modeling Perkinsus marinus infections in oysters. Journal of Shellfish Research 14:121-151.

Hofmann, E.E., E.N. Powell, J.M. Klinck, and E.A. Wilson. 1992. Modeling oyster populations. III. Critical feeding periods, growth and reproduction. Journal of Shellfish Research 11:399-416.

Hufnagel L., D. Brockmann, and T. Geisel. 2004. Forecast and control of epidemics in a globalized world. Proceedings of the National Academy of Science of the United States of America 101:15,124-15,129, doi:10.1073/pnas.0308344101.

Kennedy, V.S., and W. van Heukelme. 1986. Responses to environmental factors by larval oysters Crassostrea virginica. American Malacological Bulletin 4:101.

Kermack, W.O., and A.G. McKendrick. 1927. A contribution to the mathematical theory of epidemics. Proceedings of the Royal Society of London A 115:700-721.

Klinck, J.M., E.N. Powell, E.E. Hofmann, and M.M. Dekshenieks. 2002. Impact of channelization on oyster production: A hydrodynamicoyster population model for Galveston Bay, Texas. Environmental Modeling and Assessment 7:273-289.

Lafferty, K., and A.M. Kuris. 1993. Mass mortality of abalone Haliotis cracherodii on the California Channel Islands: Tests of epidemiological hypotheses. Marine Ecology Progress Series 96:239-248.

Lafferty, K.D., J.A. Porter, and S.E. Ford. 2004. Are diseases increasing in the ocean? Annual Review of Ecology and Systematics 35:31-54.

MacCready, P., 2004. Toward a unified theory of tidally-averaged estuarine salinity structure. Estuaries 27:561-570.

Mackin, J.G., 1956. Dermocystidium marinum and salinity. Proceedings of the National Shellfisheries Association 46:116-133.
Mackin, J.G., H.M. Owen, and A. Collier. 1950. Preliminary note on the occurrence of a new protistan parasite, Dermocystidium marinum n. sp. in Crassostrea virginica (Gmelin). Science 111:328-329.

Mann, R. 1991. Swimming rate and responses of larvae of three mactrid bivalves to salinity discontinuities. Marine Ecology Progress Series 92:107-116.

Mesinger, F., G. DiMego, E. Kalnay, K. Mitchell, P.C. Shafran, W. Ebisuzaki, D. Jovic, J. Woollen, E. Rogers, and others. 2006. North American Regional Reanalysis. Bulletin of the American Meteorological Society 87:343-360.

Milbury, C., X. Guo, D. Bushek, and S.E. Ford. 2008 Spatial population structure in Delaware Bay oysters. Journal of Shellfish Research 27(4):1033. (abstract)

Mukai, A., S. Takemoto, T. Higashi, and Y. Fukuda. 2001. Oceanic tidal loadings estimated from gravity observations in Kyoto and Bandung. Journal of the Geodynamics Society of Japan 47:261-266.

Najjar, R.G., H.A. Walker, P.J. Anderson, E.J. Barron, R.J. Bord, J.R. Gibson, V.S. Kennedy, C.G. Knight, J.P. Megonigal, R.E. O'Connor, and others. 2000. The potential impacts of climate change on the mid-Atlantic coastal region. Climate Research 14:219-233.

National Research Council (NRC). 2004. Nonnative Oysters in the Chesapeake Bay. National Academy Press, Washington, DC, 325 pp.

Nell, J.A., and R.E. Hand. 2003. Evaluation of the progeny of second-generation Sydney rock oyster Saccostrea glomerata (Gould, 1850) breeding lines for resistance to QX disease Marteilia sydneyi. Aquaculture 228:27-35.

Oke, P.R., J.S. Allen, R.N. Miller, G.D. Egbert, J.A. Austin, J.A. Barth, T.J. Boyd, P.M. Kosro, and M.D. Levine. 2002. A modeling study of the three-dimensional continental shelf circulation off Oregon. Part I: Model-data comparisons. Journal of Physical Oceanography 32:1,360-1,382.

Powell, E.N., K.A. Ashton-Alcox, J.N. Kraeuter, S.E. Ford, and D. Bushek. 2008. Long-term trends in oyster population dynamics in Delaware Bay: Regime shifts and response to disease. Journal of Shellfish Research 27:729-755.

Powell, E.N., E.E. Hofmann, and J.M. Klinck. 1996. Modeling diseased oyster populations. II. Triggering mechanisms for Perkinsus marinus epizootics. Journal of Shellfish Research 15:141-165.

Powell, E.N., E.E. Hofmann, J.M. Klinck, and S.M. Ray. 1992. Modeling oyster populations. I. A commentary on filtration rate. Is faster always better? Journal of Shellish Research 11:387-398.

Powell, E.N., J.M. Klinck, S.E. Ford, E.E. Hofmann, and S.J. Jordan. 1999. Modeling the MSX parasite in eastern oyster (Crassostrea virginica) populations. III. Regional application and the problem of transmission. Journal of Shellfish Research 18:517-537.
Powell, E.N., J. Song, M.S. Ellis, and E.A. WilsonOrmond. 1995. The status and long-term trends in oyster reefs in Galveston Bay, Texas. Journal of Shellfish Research 14:439-457.

Ragone Calvo, L.M., G.W. Calvo, and E.M. Burreson. 2003. Dual disease resistance in a selectively bred eastern oyster, Crassostrea virginica, strain tested in Chesapeake Bay. Aquaculture 220:69-87.

Rose, C.G., K.T. Paynter, and M.P. Hare. 2006. Isolation by distance in the eastern oyster, Crassostrea virginica, in Chesapeake Bay. Journal of Heredity 97:158-170, doi:10.1093/jhered/esj019.

Shchepetkin, A.F., and J.C. McWilliams. 2005. The regional oceanic modeling system (ROMS): A split-explicit, free-surface, topographyfollowing-coordinate ocean model. Ocean Modelling 9:347-404.

Smolarkiewicz, P.K., and J. Szmelter. 2005. Multidimensional positive definite advection transport algorithm (MPDATA): An edge-based unstructured-data formulation. International Journal for Numerical Methods in Fluids 47:1,293-1,295.

Stokes, N.A., J.G. Walker, and E.M. Burreson. 1996. Comparison of Haplosporidium nelsoni diagnostic techniques: Polymerase chain reaction outperforms histology. Journal of Shellfish Research 15:498. (abstract)

Taylor, K.E. 2001. Summarizing multiple aspects of model performance in a single diagram. Geophysical Research Letters 106:7,183-7,192.

Versar, Inc. 2001. Pre-construction oyster, water quality, and sediment monitoring study for the Delaware River main channel deepening project, 2000/2001. Report prepared for US Army Corps of Engineers, Contract No. DCAW61-95-D-0011. Available online at: http://www.nap.usace.army. mil/cenap-pl/drmcdp/deldocs.html (accessed October 7, 2009).

Wang, Y., and X. Guo. 2008. Mapping diseaseresistance genes in the eastern oyster (Crassostrea virginica). Journal of Shellfish Research 27(4):1,0611,062. (abstract)

Whitney, M., and R. Garvine. 2006. Simulating the Delaware Bay buoyant outflow: Comparison with observations. Journal of Physical Oceanography 36:3-21.

Wong, K.-C., 1994. On the nature of transverse variability in a coastal plain estuary. Journal of Geophysical Research 99:14,209-14,222.

Yu, Z., and X. Guo. 2006. Identification and mapping of disease-resistance QTL in the eastern oyster, Crassostrea virginica Gmelin. Aquaculture 254:160-170.

Zhang, L., X. Guo, D. Bushek, and S.E. Ford. 2008. Mapping quantitative trait loci conferring Dermo resistance in the eastern oyster Crassostrea virginica. Journal of Shellfish Research 27(4):1067. (abstract) 